\title{
Complejo volcánico Nadó, norte del graben de Acambay: evidencias de magmatismo oligocénico y su relación con el sector central del Cinturón Volcánico Transmexicano
}

\author{
Jesús Cabrera-Román ${ }^{1}$, Javier Castro-Segura1, Gabriel Valdez-Moreno ${ }^{1, *}$ y José Luis Arce-Saldaña ${ }^{2}$
}

${ }^{1}$ Unidad Académica de Ciencias de la Tierra, Universidad Autónoma de Guerrero, Ex Hacienda San Juan Bautista, Taxco El Viejo, Guerrero, México.

${ }^{2}$ Departamento de Procesos Litosféricos, Instituto de Geología, Universidad Nacional Autónoma de México, Ciudad Universitaria, Delegación Coyoacán, Ciudad de México, 04510, México.

*valdezm@unam.mx

\section{RESUMEN}

El complejo volcánico Nadó (CVÑ) se localiza en el sector central del Cinturón Volcánico Transmexicano (CVTM) y al norte del graben de Acambay, en los estados de Querétaro y México. Este complejo se compone de 11 unidades litológicas, las cuales se agruparon en tres secuencias (1. pre-Ñadó, 2. Ñadó y 3. post-Ñadó). La unidad más antigua es la Riolita La Florida (etapa 1. pre-Ñadó), fechada por el método U-Pb en circones en $30.81 \pm 0.17 \mathrm{Ma}$ y $31.71 \pm 0.27 \mathrm{Ma}$, la cual puede ser atribuida a los pulsos de magmatismo félsico de la Sierra Madre Occidental (SMO) emplazados durante el Oligoceno. El resto de las secuencias se puede correlacionar temporalmente con los episodios de vulcanismo del Mioceno tardío en el CVTM, propuestos en trabajos previos. El estratovolcán Nadó (etapa 2. Ñadó) se edificó a finales del Mioceno y se caracterizó por múltiples eventos efusivos, de composición dacítica, constituidos por varios derrames lávicos viscosos y emplazamiento de una espina (Peña Nadó) y un domo (Cerro Pelón). Contemporáneamente se registraron eventos de vulcanismo máfico que formaron conos de escoria y emplazamiento de derrames basálticos. La etapa post-Ñadó consiste en una serie de lavas andesíticas e ignimbritas provenientes de las calderas de Amealco y Huichapan, vulcanismo máfico y depósitos de lahares. Adicionalmente, se reportan depósitos de caída asociados al volcán Temascalcingo. Geoquímicamente, las rocas muestran rasgos típicos de una zona de subducción de arco magmático continental, como enriquecimiento en los elementos litófilos de ion grande (LILE) con respecto a los elementos de alto potencial iónico (HFSE), anomalías negativas de $\mathrm{Nb}$, Ta, $\mathrm{P}$ y Ti, así como, anomalías positivas en $\mathrm{Ba}, \mathrm{K}, \mathrm{Pb}$ y $\mathrm{Sr}$. Los elementos de las tierras raras (REE) presentan un enriquecimiento de REE ligeras con respecto a las pesadas, mientras que la Riolita La Florida presenta patrones de REE con la típica forma de "gaviota" y una anomalía negativa muy marcada en $\mathrm{Eu}$, lo que sugiere una génesis diferente al resto de las rocas. Las variaciones geoquímicas del volcán Ñadó pueden ser explicadas por el proceso petrológico de AFC.

Palabras clave: Geoquímica; volcán Nadó; Cinturón Volcánico Transmexicano.

\begin{abstract}
The Nado Volcanic Complex is located in the central sector of the Transmexican Volcanic Belt (TMVB), to the north of the active Acambay graben, in the states of Querétaro and México. This complex is formed by 11 stratigraphic units, which were subdivided into three sequences (1. pre-Nadó, 2. Nadó, and 3. post-Ñadó). The oldest unit of the pre-Ñadó sequence (La Florida Rhyolite) was dated at $30.81 \pm 0.17 \mathrm{Ma}$ and 31.71 $\pm 0.27 \mathrm{Ma}$ by the $\mathrm{U}-\mathrm{Pb}$ method in zircon, and can thus be related to the Oligocene felsic magmatism of the Sierra Madre Occidental (SMO). All other sequences can be temporarily correlated with previously reported episodes of late Miocene volcanism in the TMVB. The Nadó composite volcano was built up during late Miocene by multiple effusive events of dacitic composition, including the emplacement of several lava flows, a spine (Peña Ñadó), and a dome (Cerro Pelón). This acid volcanism was contemporaneous with mafic volcanism, represented by scoria cones and basaltic lava flows. Finally, the post-Nadó stage is represented by a series of andesites, ignimbrites from Amealco and Huichapan Calderas, mafic volcanism, lahars and fall deposits from Temascalcingo volcano. The geochemistry of the rocks shows some typical characteristics of subduction zones, such as enrichment in large ion lithophile elements (LILE) compared to high field strength elements (HFSE), negative anomalies of $\mathrm{Nb}, \mathrm{Ta}, P$, and $\mathrm{T} i$, as well as positive anomalies of $\mathrm{Ba}, K, \mathrm{~Pb}$ y $\mathrm{Sr}$. The rare earth elements (REE) show an enrichment of light REE with respect to heavy $R E E$, except for the Oligocene La Florida rhyolites, which show REE patterns with a typical "seagull" shape, which suggests a different origin compared with the younger samples. Geochemical characteristics suggest that the main petrological mechanism during the Nadó evolution was the AFC.
\end{abstract}

Key words: geochemistry; Nadó volcano; Trans-Mexican Volcanic Belt.

\section{INTRODUCCIÓN}

El complejo volcánico Nadó (CVÑ), se localiza en la porción central del Cinturón Volcánico Transmexicano (CVTM), un arco magmático continental ampliamente estudiado y de gran interés debido 
a sus características únicas en el mundo, como el ángulo de aproximadamente $15^{\circ}$ entre la zona de subducción y el arco continental (e.g., Pardo y Suárez, 1995). Durante varias décadas se ha publicado un gran número de investigaciones acerca de su origen y evolución, geoquímica y petrogénesis. Sin embargo, los estudios han demostrado que aún se requiere información para contribuir al entendimiento de la evolución de este arco magmático, en especial sobre sus etapas evolutivas iniciales. A través de diversos estudios se sabe que los volcanes más antiguos se han documentado al norte del CVTM (e.g., Pérez-Venzor et al., 1996; Valdez-Moreno et al., 1998; Carrasco-Núñez et al., 1989; Gómez-Tuena y Carrasco-Núñez, 2000), mientras que los centros volcánicos activos se localizan al sur del CVTM, justo en el frente del arco volcánico, como los volcanes de Colima y Popocatépetl, los cuales han sido ampliamente estudiados por varios investigadores (e.g., Luhr, 2002; Macías et al., 2017; Siebe et al., 1996; Schaaf et al., 2005). Recientemente se han documentado rocas del Mioceno temprano en la parte sur del arco, como la Formación Tepoztlán de 22.8-13 Ma (Lenhardt et al., 2010), las trondhjemitas de Chalcatzingo de $21.00 \pm 0.15 \mathrm{Ma}$ (GómezTuena et al., 2008), así como otros cuerpos volcánicos localizados en el subsuelo de la Cuenca de México (ubicados en la parte centro del arco) que oscilan desde los 20.1 Ma hasta el Reciente (Arce et al., 2013). En este contexto falta aún estudiar con mayor detalle la petrología y geoquímica del volcanismo miocénico del sector central del CVTM, y así poder definir mejor su evolución.

En este trabajo se presenta la estratigrafía del complejo volcánico Ñadó, situado en la región central del CVTM (Figura 1), el cual consiste de varias estructuras y diferentes litologías, por lo que se ha clasificado como un complejo volcánico conformado por derrames de lava andesítica y dacítica, así como domos riolíticos. Adicionalmente se encuentran conos de escoria de composición basáltica emplazados al sur y este del complejo, así como ignimbritas de las calderas de Amealco y Huichapan (Aguirre-Díaz, 1996). En este trabajo se documenta por primera vez la edad de los productos volcánicos más antiguos reportados hasta ahora en la región, la petrografía, geoquímica, la petrología de los productos del CVÑ y se discute su relación con las etapas de formación del CVTM reportadas por Gómez-Tuena et al. (2005).

\section{GEOLOGÍA REGIONAL Y CONTEXTO TECTÓNICO}

El Cinturón Volcánico Transmexicano (CVTM) se define como un arco magmático continental activo asociado a la subducción de las placas de Cocos y Rivera por debajo de la placa de Norteamérica (e.g., Nixon, 1982; Demant, 1981; Pardo y Suárez, 1995; Ferrari, 2000; Gómez-Tuena et al., 2005). La edad del CVTM sigue siendo un tema de discusión (e.g., Mooser, 1972; Demant, 1978; Cantagrel y Robin, 1979; Demant, 1981; Robin y Cantagrel, 1982; Venegas et al., 1985; Nixon et al., 1987), sobre todo por la transición espaciotemporal entre la Sierra Madre Occidental (SMO) y el Cinturón Volcánico Transmexicano (Ferrari et al., 1999). En la actualidad, debido a los abundantes fechamientos isotópicos realizados en las últimas décadas, todo parece indicar que la individualización del CVTM como una entidad geológica distintiva ocurrió durante el Mioceno medio y tardío, como resultado de una rotación antihoraria del arco que formó la Sierra

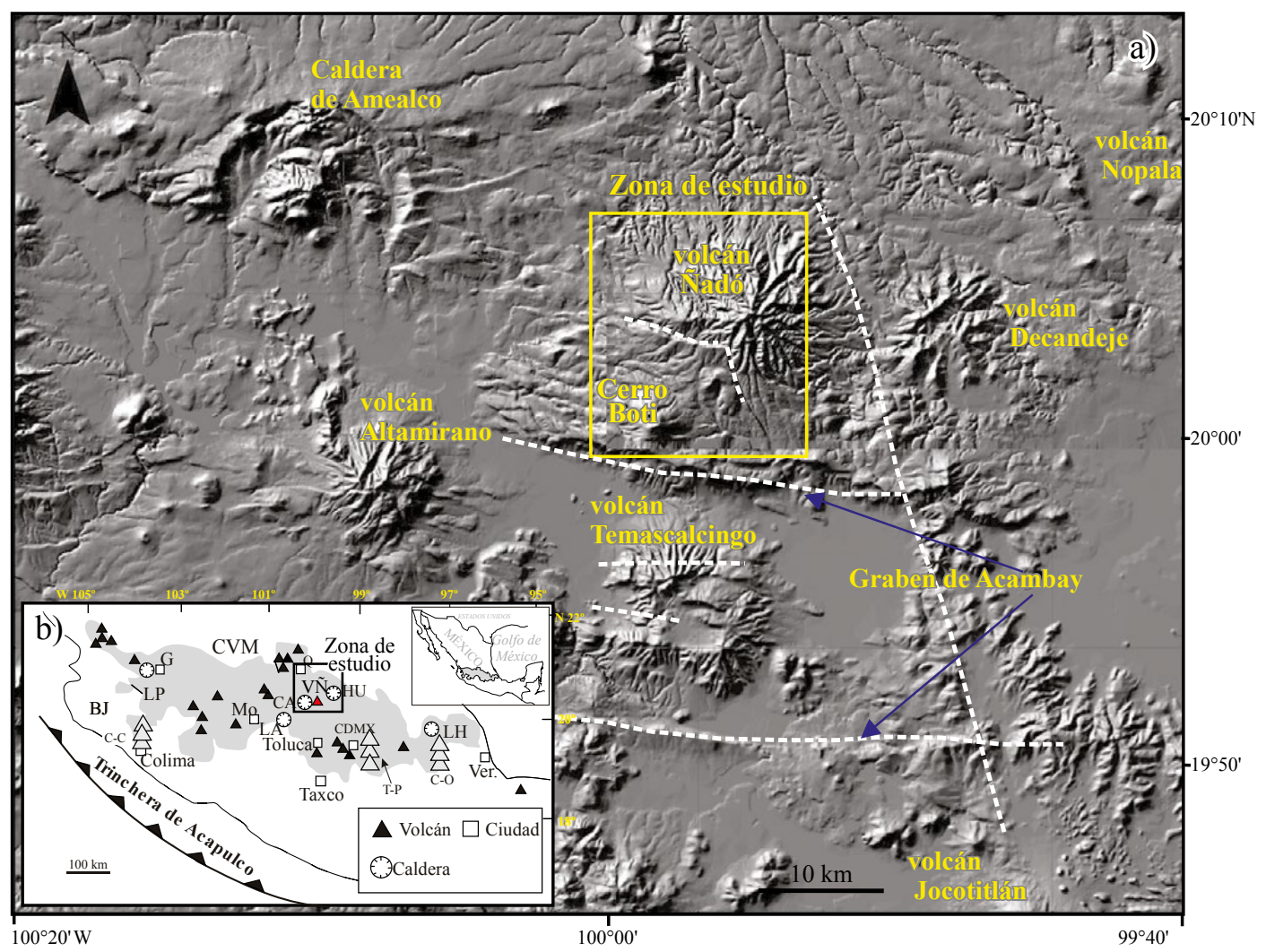

Figura 1. a) Modelo digital de elevación del área de estudio, en el que se muestran las estructuras volcánicas principales, así como los sistemas de fallas E-O y NO-SE (líneas punteadas). El recuadro en color amarillo representa el área del mapa de la Figura 2; b) Localización del Cinturón Volcánico Transmexicano, con los principales volcanes y ciudades. LP: La primavera, C-C: Complejo Colima, CA: Caldera de Amealco, LA: Los Azufres, TP: Telapón-Popocatépetl, LH: Los Humeros, C-O: Cofre de Perote-Orizaba. G: Guadalajara, Mo: Morelia, Q: Querétaro, Ver: Veracruz. El recuadro corresponde al área del inciso a) (modificado de Aguirre-Díaz, 1996). 
Madre Occidental (Ferrari et al., 1999). Sin embargo, fechamientos recientes sugieren que el inicio del vulcanismo del CVTM tuvo lugar entre 21.5 Ma y 22.8 Ma (Lenhardt et al., 2010). De igual manera, en pozos profundos perforados en la Cuenca de México (sector central) se han documentado rocas volcánicas antiguas de $20.1 \mathrm{Ma}$ (Arce et al., 2013) que coinciden con los fechamientos de la Formación Tepoztlán.

Gómez-Tuena et al., (2005) sintetizan la evolución geológica del CVTM en cuatro episodios principales: (1) el establecimiento de un arco de composición intermedia en el Mioceno medio y tardío, (2) un episodio máfico del Mioceno tardío, (3) un episodio silícico de finales de Mioceno, que llega a ser bimodal en el Plioceno temprano y (4) la formación de un arco moderno con gran variabilidad composicional a partir del Plioceno tardío. Debido a sus características estructurales Demant (1978) y Pasquaré et al. (1988) dividieron al CVTM en tres sectores, 1 . Occidental, 2. Central y 3. Oriental. En el sector central se localiza el graben de Acambay, una estructura orientada E-O y asociada a extensión intra-arco, la cual se ha identificado como sísmicamente activa (Suter et al., 1995; Quintero-Legorreta, 2002; Sunyé-Puchol et al., 2015). Al norte del graben de Acambay se sitúa un grupo de estratovolcanes de más de 3000 m s.n.m. Entre los que destacan el Altamirano, Temascalcingo, Nopala, Decandeje y Ñadó (Figura 1). En la parte oeste se encuentra la Caldera de Amealco, la cual ha sido investigada en detalle por Aguirre-Díaz y Mc Dowell (2000). La estratigrafía de esta zona fue estudiada a escala regional por Silva-Mora, (1997), con el reconocimiento de varios eventos volcánicos documentados desde el Eoceno hasta el Pleistoceno, y en los cuales se identificaron varias estructuras volcánicas, así como la caracterización de sus productos emitidos.

En la región central se han documentado rocas de composición basáltica, andesítica y dacítica emplazadas entre el Mioceno y Pleistoceno con edades que varían de 9 a 6 Ma (Silva-Mora, 1997), las cuales corresponden a las más antiguas de la región. Sánchez-Rubio (1984) reportó edades K-Ar de 8.5 Ma y de 5 Ma para la andesita de Aculco. Edades de volcanismo más reciente han sido reportadas por Aguirre-Díaz y López-Martínez (2001) para ignimbritas de la caldera

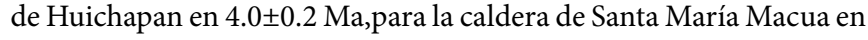
3.5 Ma (Aguirre-Díaz, 2001) y para el volcán Nopala en $2.4 \pm 0.2 \mathrm{Ma}$ (Aguirre-Díaz et al. 1997).

Desde el punto de vista estructural el CVÑ se localiza al norte del graben de Acambay (Figura 1), el cual está delimitado por fallas E-O (Suter et al., 1992). En esta región se observa además un lineamiento NO-SE, probablemente asociado a una falla regional, que se extiende al norte del volcán Jocotitlán y se proyecta hacia el este del volcán Ñadó (Figura 1). Este mismo sistema NO-SE coincide con el alineamiento de los conos de escoria localizados entre los volcanes Nadó y Decandeje (Figuras 1 y 2). Por su dirección es probable que pertenezca al sistema de fallas Taxco-San Miguel de Allende (Alaniz-Álvarez y Nieto Samaniego, 2005).

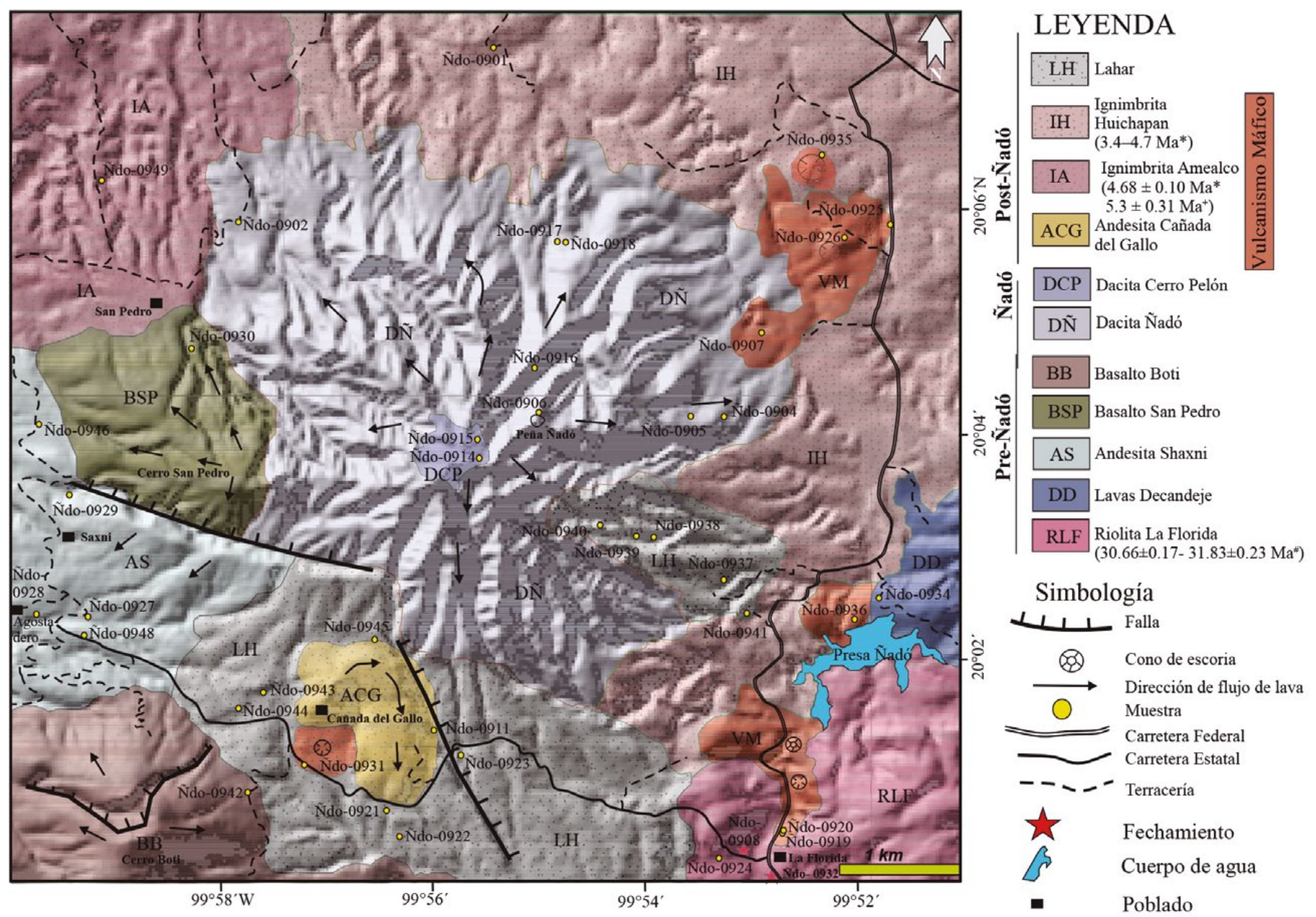

Figura 2. Mapa geológico del complejo volcánico Ñadó (CVÑ), elaborado con base en algunos datos previos y datos nuevos de este trabajo. ${ }^{\star}$ Edades reportadas en Aguirre-Díaz (1996) y Norini et al. (2010); 'Edad reportada en Aguirre-Díaz y López-Martínez (2001); "Edad que se reporta en este trabajo. 


\section{METODOLOGÍA Y TÉCNICAS ANALÍTICAS}

Durante el trabajo de campo y colecta de muestras se obtuvieron de 3 a $4 \mathrm{~kg}$ de esquirlas trituradas hasta obtener fragmentos de $\sim 4-5 \mathrm{~cm}$ para análisis químico y de 10 a $20 \mathrm{~kg}$ para separar circones y fechar las rocas. Posteriormente, cada ejemplar fue analizado petrográficamente para asegurarse que estuviera lo más fresco posible y sin alteraciones.

En el laboratorio, cada muestra fue lavada con agua bidestilada para eliminar todos los restos de polvo y materia orgánica. Posteriormente fueron secadas en un horno durante 3 a 4 horas a una temperatura de $100{ }^{\circ} \mathrm{C}$. Se procedió a la trituración de las muestras en la quebradora de quijadas, hasta obtener fragmentos menores a un centímetro. Finalmente se pulverizaron para ser analizadas.

Para elementos mayores se analizaron un total de 17 muestras por Fluorescencia de Rayos-X en el Laboratorio Nacional de Geoquímica y Mineralogía de la Universidad Nacional Autónoma de México (UNAM), siguiendo el procedimiento descrito por Lozano-Santa Cruz et al. (2005) y 17 ejemplares para elementos traza por ICP-MS (Inductively Coupled Plasma Mass Spectrometry) en el Laboratorio de Estudios Isotópicos del Centro de Geociencias, UNAM-Campus Juriquilla siguiendo el procedimiento establecido por Mori et al. (2007). Los resultados de los análisis se reportan en las Tablas 1 y Tabla A1 del suplemento electrónico.

Las edades $\mathrm{U}-\mathrm{Pb}$ en circones se obtuvieron en el Laboratorio de Estudios Isotópicos, del Centro de Geociencias de acuerdo con el procedimiento publicado por Solari et al. (2015). Los resultados se reportan en la Tabla A2 del suplemento electrónico.

\section{GEOLOGÍA DEL COMPLEJO VOLCÁNICO ÑADÓ}

El complejo volcánico Nadó (3380 m s.n.m.) está conformado por una secuencia de derrames de lava de composición dacítica con distribución radial y, por domos centrales dacíticos (Cerro Pelón y Peña Nadó). Las lavas basálticas de la etapa pre-Ñadó (Basalto San Pedro) afloran hacia el este del edificio central (Figura 2). El rasgo distintivo es la presencia de una espina de composición dacítica llamada "Peña Nadó" de la cual toma el nombre. El complejo está rodeado por diferentes unidades litológicas que se describen más adelante. De acuerdo con las relaciones estratigráficas, estudios petrográficos y análisis geoquímicos se pudieron determinar 11 unidades litológicas para esta área de estudio, las cuales se agruparon en tres secuencias: 1. pre-Ñadó, 2. Ñadó y 3. post-Ñadó (Figura 2).

\section{Secuencia pre-Ñadó}

\section{Riolita La Florida}

Se denomina con el nombre informal Riolita La Florida a un conjunto de domos riolíticos que afloran en la parte sureste del área de estudio, cerca del poblado La Florida, a los costados de la carretera federal que conduce a la comunidad de Aculco de Espinoza, Estado de México (Figura 2). A escala de afloramiento, la roca se observa muy fracturada, resultado de un proceso de enfriamiento y de deformación post-emplazamiento por el sistema de fallas de Acambay (Figura 3a). En roca sana presenta colores de rosa claro a rojizo que cambia de gris oscuro a verde oscuro por intemperismo. En muestra de mano se observa una textura porfídica, con una mineralogía constituida de cuarzo, sanidino, plagioclasa y biotita.

En el microscopio se observa una textura porfídica, con un grado de cristalinidad hipocristalino. En general, las rocas muestran una asociación mineralógica conformada en orden de abundancia por fenocristales de cuarzo, sanidino, plagioclasa y biotita, embebidos en una matriz de vidrio (Figura $3 b$ ). Cabe destacar que se observaron cristales parcialmente oxidados, con relieve alto, fracturados, que fueron clasificados como fenocristales de fayalita.

\section{Lavas Decandeje}

Esta unidad consiste en andesitas y dacitas que afloran al oeste del poblado Decandeje y constituyen la unidad principal del volcán del mismo nombre (Figura 1). En el mapa (Figura 2) esta unidad aflora de manera restringida en la parte sureste, en donde presenta un espesor aproximado de $25 \mathrm{~m}$ (Figura 3c). En muestra de mano la roca intemperizada presenta un color verde, mientras que en roca sana tiene un color gris oscuro. Presenta una textura porfídica con cristales de plagioclasa y piroxeno, inmersos en una matriz de grano fino.

Tabla 1. Concentración de los elementos mayores en \% en peso en las muestras del complejo volcánico Nadó.

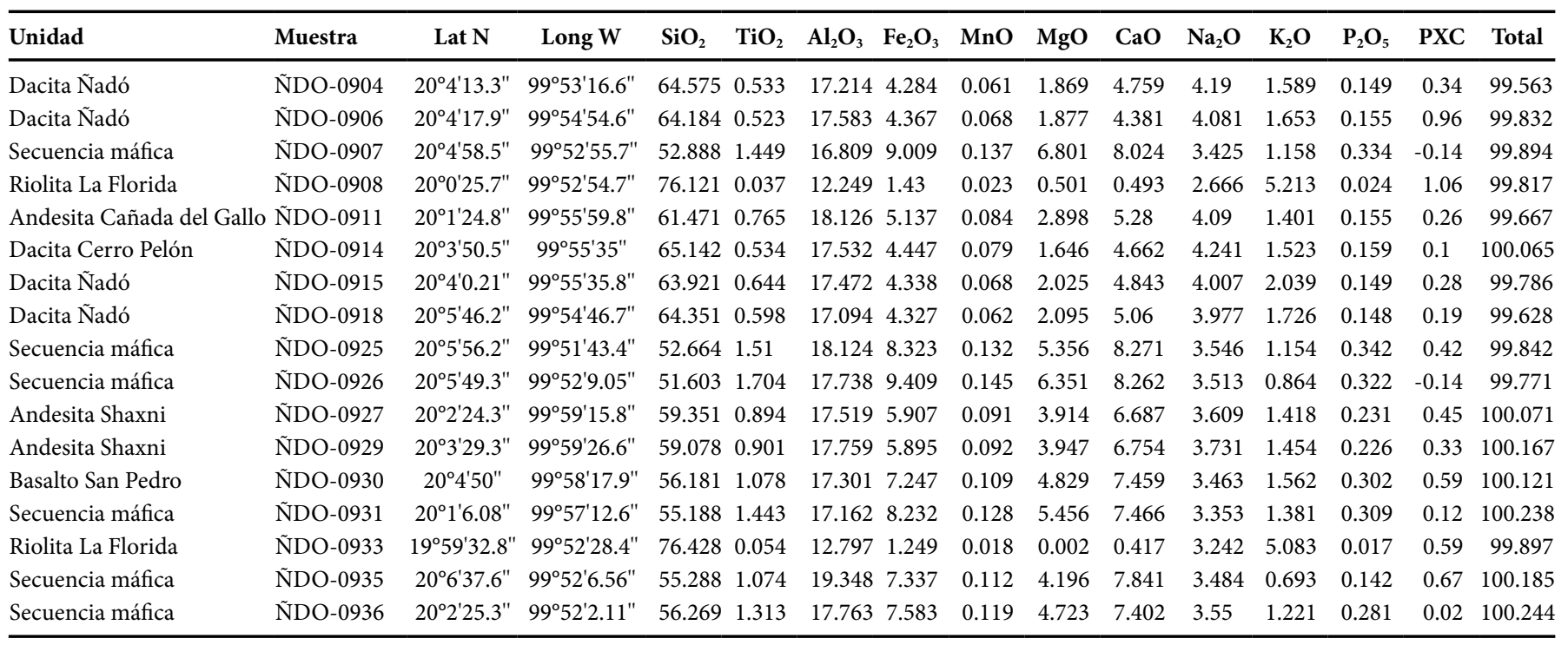

PXC: Pérdida por calcinación 

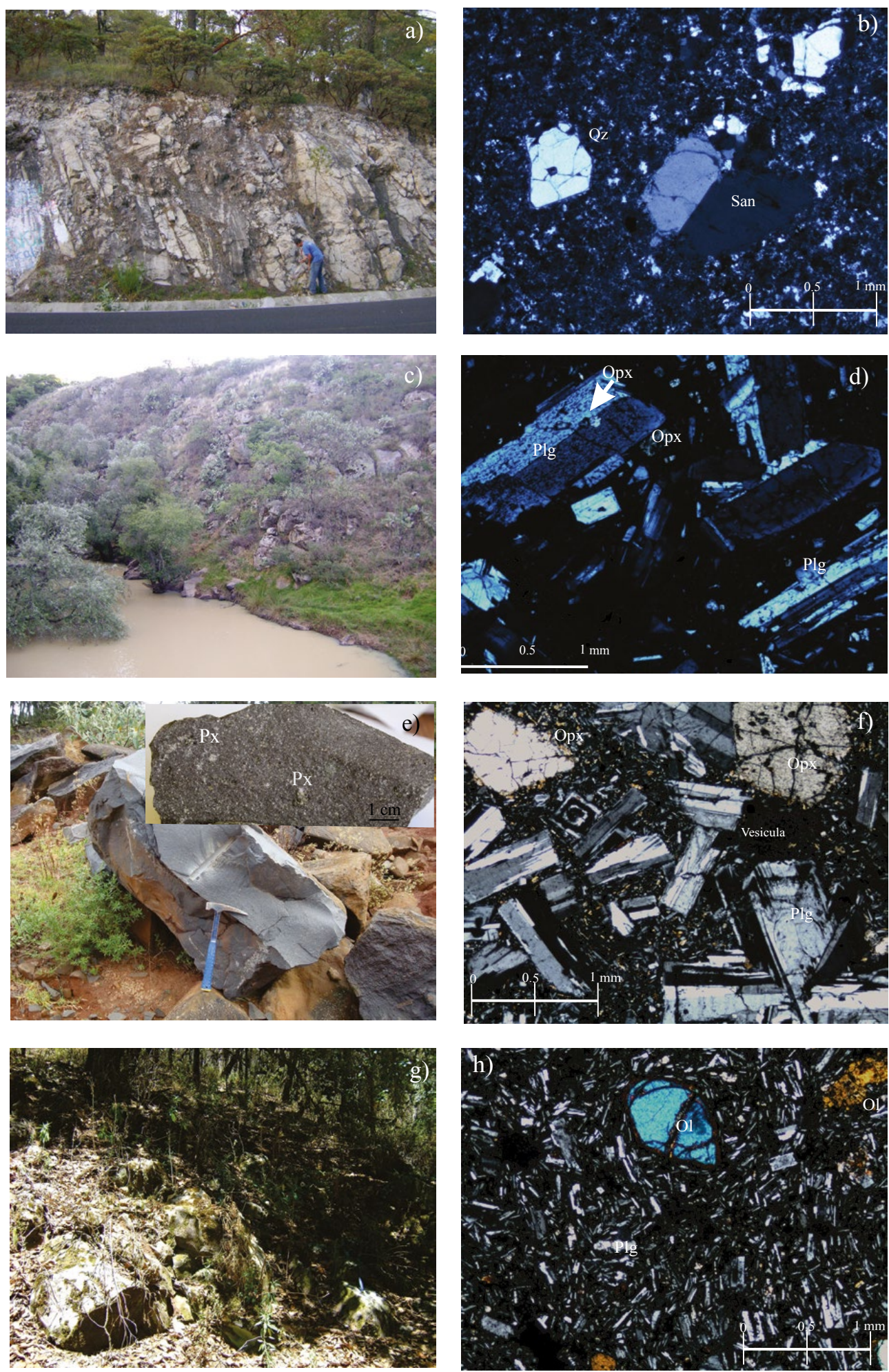

Figura 3. Unidades de la secuencia pre-Ñadó. a) Afloramiento representativo de la unidad Riolita La Florida, el cual exhibe un intenso fracturamiento. b) Microfotografía de la Riolita La Florida, en la que se muestran la textura porfídica con fenocristales de cuarzo (Qz) y sanidino (San) con macla carlsbad, inmersos en matriz de grano más fino. La muestra corresponde a la clave ÑDO-0908. c) Afloramiento de la andesita Decandeje, localizado en la compuerta de la presa Ñadó; se observan bloques mayores a $2 \mathrm{~m}$ y un espesor de esta unidad superior a los $9 \mathrm{~m}$. d) Textura porfídica con fenocristales subédricos y euédricos de plagioclasa (Plg) y ortopiroxeno (Opx) embebidos en una matriz formada por microlitos de plagioclasa y vidrio en la andesita Decandeje, la cual corresponde a la muestra ÑDO0934. e) Unidad andesita Shaxni en la que se pueden apreciar bloques de tonalidad gris oscuro con fenocristales grandes de piroxeno ( $2 \mathrm{~mm}$, recuadro superior derecho). f) Microfotografía de la andesita Shaxni (ÑDO-0929) en la que se observa la textura porfídica con fenocristales euédricos y subédricos de plagioclasa (Plg) y ortopiroxeno (Opx), embebidos en microlitos de plagioclasa y vidrio. g) Afloramiento de la unidad basalto San Pedro, localizado en la población del mismo nombre. Se observan bloques mayores a $1 \mathrm{~m}$ de color gris claro y parcialmente cubiertos por vegetación. h) Microfotografía del basalto San Pedro (ÑDO-930), el cual exhibe una textura porfídica, con fenocristales de olivino $(\mathrm{Ol})$ y plagioclasa $(\mathrm{Plg})$, inmersos en una matriz formada por microlitos de plagioclasa. 
Al microscopio es hipocristalina y exhibe una textura porfídica, con un ensamble mineral constituido por plagioclasa y ortopiroxeno, embebidos en una matriz de vidrio y microlitos de plagioclasa (Figura $3 \mathrm{~d})$. Ocasionalmente se pueden observar glomerocristales de plagioclasa y ortopiroxeno de hasta $1.5 \mathrm{~mm}$ de longitud.

\section{Andesita Shaxni}

La andesita Shaxni recibe el nombre por la localidad donde aflora, la cual se localiza en la parte suroeste del área de estudio (Figura 2). Esta unidad presenta afloramientos de espesor variable, de 20 hasta 50 m. Las lavas se encuentran lajeadas y en ocasiones masivas (Figura 3e). Presentan un color de intemperismo café oscuro y en fractura fresca gris claro, con textura invariablemente porfídica. La mineralogía que se observa está constituida por cristales de plagioclasa, ortopiroxeno, clinopiroxeno, escasa hornblenda y minerales opacos (titanomagnetita), todos estos embebidos en una matriz compuesta por microlitos de plagioclasa y vidrio (Figura $3 f$ ).

\section{Basalto San Pedro}

El basalto San Pedro se localiza en la parte oeste del área de estudio, cerca del poblado San Pedro (Figura 2). Esta unidad está formada por derrames de lava que fluyeron principalmente en dirección al sur y hacia el NO del área de estudio. Los afloramientos de esta unidad son escasos, ya que se encuentran cubiertos por vegetación (Figura 3g). Sin embargo, se observó que la roca presenta una textura porfídica, con un color de intemperismo verdoso, mientras que en fractura fresca presenta un color gris oscuro. La mineralogía está conformada por olivino, plagioclasa y minerales opacos, mismos que están embebidos en una matriz de vidrio y microlitos de plagioclasa. El olivino se observa con abundantes inclusiones de cromita (Figura $3 \mathrm{~h}$ ).

\section{Basalto Boti}

Esta unidad conforma el Cerro Boti, el cual presenta una elevación aproximada de $3300 \mathrm{~m}$ s.n.m. y se localiza en la parte suroeste del área de estudio. Se caracteriza por una secuencia de derrames de lava masiva, de al menos $3 \mathrm{~m}$ de espesor. Este cerro tiene una morfología suave y de forma abombada, por lo que es fácil distinguirlo (Figura 2). Con ayuda de imágenes satelitales y ortofotos fue posible determinar que la parte central de este cerro está afectada por una posible estructura de colapso con dirección principal E-O, probablemente asociado con el sistema de fallas del graben de Acambay. En muestra de mano, la lava tiene un color de intemperismo verde oscuro y gris oscuro en corte fresco, exhibe una textura porfídica con una mineralogía de plagioclasa, clinopiroxeno, olivino y ortopiroxeno; también se observa la presencia de apatito como mineral accesorio. Los minerales están inmersos en una matriz constituida por vidrio, microlitos de plagioclasa y clinopiroxeno. Raramente se observan glomerocristales de plagioclasa y clinopiroxeno.

\section{Secuencia Nadó}

\section{Dacita Nadó}

La dacita Nadó corresponde a la unidad litológica más importante debido a que es el principal constituyente del volcán (Figura 2; 4a). La unidad está caracterizada por una secuencia de derrames de lavas dacíticas, distribuidas radialmente (Figura 2). En las faldas del volcán se observaron varios derrames de hasta $20 \mathrm{~m}$ de espesor, masivos y con alto grado de intemperismo. En las partes altas de la estructura volcánica se observaron derrames de lava lajeados, con espesores mayores a $10 \mathrm{~m}$. En muestra de mano, la roca presenta un color de intemperismo gris oscuro a café, mientras que en roca sana se observa un color gris claro. La textura es porfídica, con una mineralogía constituida en orden de abundancia por plagioclasa, ortopiroxeno (hiperstena), cuarzo, biotita, clinopiroxeno (augita) y apatito como mineral accesorio. Todos los minerales se encuentran inmersos en una matriz de vidrio de color café, microlitos de plagioclasa y ortopiroxeno. El cuarzo solo se encontró en tres muestras (ÑDO-0906, NDO-0915 y ÑDO0916), a diferencia de la biotita que solo está ausente en las muestras ÑDO-0902 y ÑDO-0918. Así mismo, la augita solo se encuentra en la muestra ÑDO-0902. Dos características notables son la presencia de intercrecimientos de cuarzo con plagioclasa y biotita (Figura $4 \mathrm{~b}$ ) y la presencia de ortopiroxeno reemplazado por biotita.

\section{Domo Cerro Pelón}

Este domo tiene una altura de $3200 \mathrm{~m}$ s.n.m. y posiblemente representa el último evento efusivo del volcán Nadó debido a su morfología y posición estratigráfica (Figura 2). A nivel de afloramiento se observan espesores de al menos $40 \mathrm{~m}$ y se presenta una estructura lajeada, la roca exhibe colores de intemperismo gris oscuro a verdoso y en fractura fresca gris claro (Figura $4 \mathrm{c}$ ). La textura es porfídica con un ensamble mineralógico de plagioclasa zonada y con inclusiones de apatito, ortopiroxeno y biotita. Resalta en la muestra la presencia de matriz microgranular (Figura 4d). Es común observar a la biotita en los bordes de los ortopiroxenos.

\section{Secuencia Post-Ñadó}

\section{Vulcanismo máfico}

De acuerdo con fotointerpretación y observaciones de campo, el vulcanismo máfico tuvo lugar en distintos periodos, ya que algunos depósitos sobreyacen a la unidad Dacita Ñadó, en otros casos subyacen a la ignimbrita Huichapan y en otras sobreyacen a esta misma ignimbrita. Las rocas de este vulcanismo se encuentran localizadas en los alrededores de la estructura principal Nadó, especialmente desde el noreste a suroeste (Figura 2). La unidad está conformada por una serie de conos de escoria, asociados a depósitos de caída de escoria, que muy cerca del cono llegan a medir de 30 a $80 \mathrm{~m}$ de espesor y por derrames de lava de composición basáltica (Figura 4e). Los depósitos de caída presentan fragmentos del tamaño lapilli a bloques con algunas bombas volcánicas incrustadas de $20 \mathrm{~cm}$ a $30 \mathrm{~cm}$ en diámetro. Las rocas en general presentan un color café rojizo al intemperismo y un color gris oscuro en roca sana. En muestra de mano, las lavas presentan una textura vesicular, con una mineralogía de plagioclasa y olivino. En algunas ocasiones se observaron xenocristales de cuarzo de tamaño variable $(0.5 \mathrm{~mm}$ a $1 \mathrm{~cm})$. Los derrames de lava se presentan en espesores mayores a $4 \mathrm{~m}$, con un color de intemperismo gris claro a rojizo y en fractura fresca exhibe una tonalidad gris oscura. La lava es hipocristalina, con amplias variaciones texturales en las muestras colectadas, desde textura porfídica, glomeroporfídica, traquítica, intergranular e intersertal. La asociación mineral en orden de abundancia es de plagioclasa, olivino, total o parcialmente idingsitizado y con inclusiones de cromita, ortopiroxeno y clinopiroxeno, todos inmersos en una matriz de vidrio café y microlitos de plagioclasa (Figura 4f).

\section{Andesitas Cañada del Gallo}

La andesita Cañada del Gallo aflora en la parte sur del área de estudio y subyace a depósitos de lahar. Este derrame de lava tiene una distribución semicircular, probablemente debido a que durante su emplazamiento cambió de dirección al chocar con una unidad previa representada por la dacita Ñadó (Figura 2). La unidad presenta un espesor de al menos $30 \mathrm{~m}$. A nivel de afloramiento exhibe una estructura masiva y en otros sitios se presenta lajeada (Figura $4 \mathrm{~g}$ ). La lava se caracteriza por un color de intemperismo café rojizo, mientras que en roca sana tiene un color gris oscuro. Es hipocristalina, con textura 

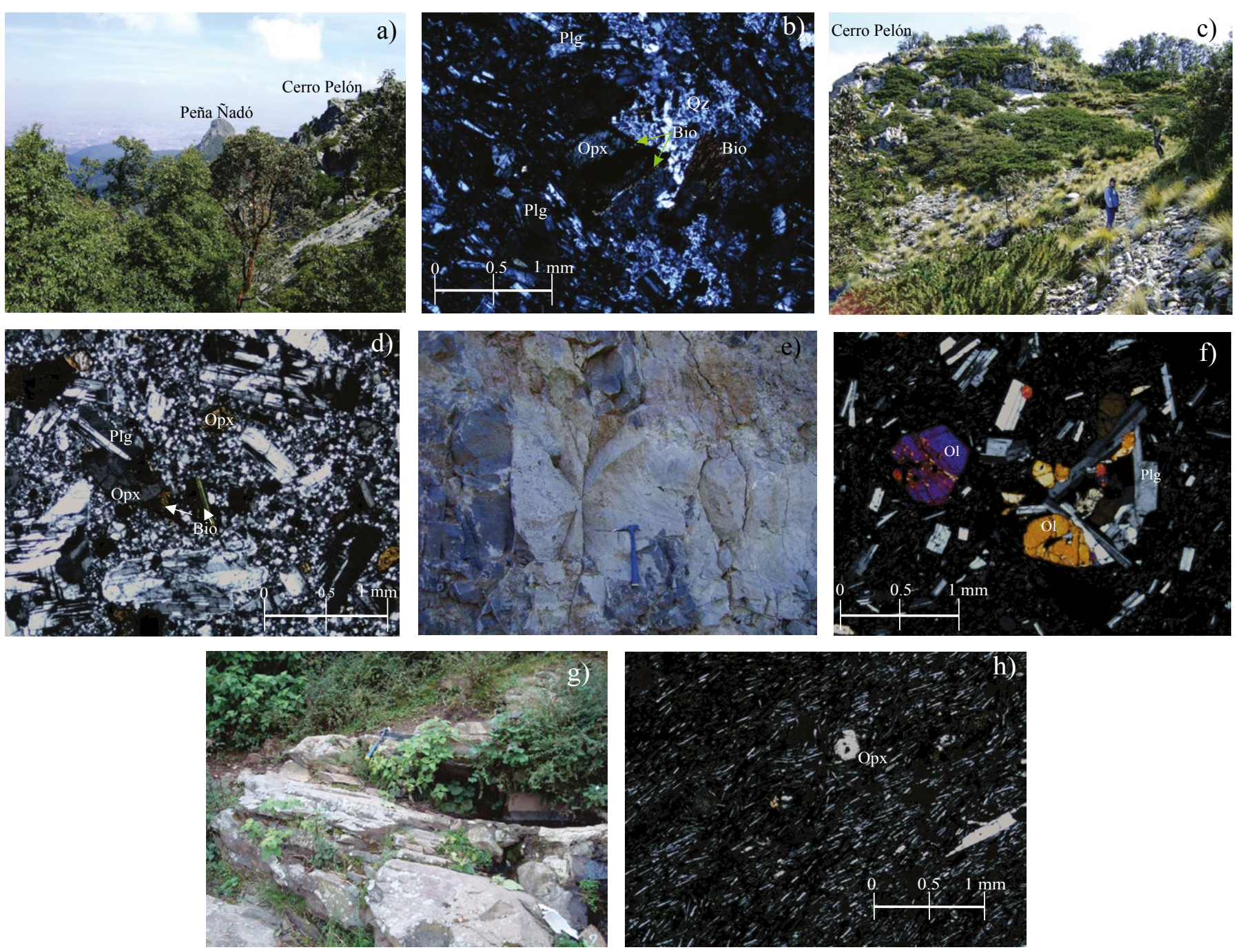

Figura 4. Unidades de la secuencia Ñadó y post-Nadó. a) Vista panorámica hacia el norte desde la cima del volcán Nadó, en donde se aprecian la Peña Ñadó y el domo Cerro Pelón. b) Microfotografía de la unidad dacita Ñadó (ÑDO-906), en la que se observan intercrecimientos de cuarzo (Qz) y plagioclasa (Plg) y biotita (Bio), fenocristales de plagioclasa (Plg) y ortopiroxeno (Opx) en una matriz de microlitos de plagioclasa y vidrio. c) Fotografía del Cerro Pelón; lava de color gris claro y de estructura masiva. d) Fenocristales euédricos de plagioclasa (Plg) y ortopiroxeno (Opx) inmersos en matriz microgranular, en la dacita domo Cerro Pelón (ÑDO-0914). Nótese la presencia de biotita en los bordes del ortopiroxeno. e) Fotografía de un afloramiento correspondiente al vulcanismo máfico, en donde se observa un derrame de lava masiva, emitido por un cono de escoria. f) Microfotografía que muestra la textura porfídica, con fenocristales de olivino (Ol) y plagioclasa (Plg) embebidos en una mesostasis de microlitos de plagioclasa y vidrio de productos del vulcanismo máfico (ÑDO-0926). g) Fotografía de un afloramiento de la unidad Cañada del Gallo, el cual presenta lavas con una estructura lajeada, de color gris claro. h) Microfotografía de la andesita Cañada del Gallo. Se observan fenocristales subédricos de ortopiroxeno (Opx) inmersos en una mesostasis constituida por microlitos de plagioclasa orientados (ÑD-0911).

porfídica, hialopilítica y subtraquítica (Figura 4h). El arreglo mineral está constituido por plagioclasa, ortopiroxeno y clinopiroxeno, todos embebidos en una mesostasis de vidrio café y microlitos de plagioclasa.

\section{Ignimbrita Amealco}

Aguirre Díaz (1996) define a esta unidad como la Toba Amealco, la cual consiste de una secuencia piroclástica asociada a la formación de la caldera de Amealco, hace aproximadamente $4.68 \pm 0.10 \mathrm{Ma}$. La secuencia piroclástica incluye tres unidades de ignimbritas soldadas muy extensas, intercaladas con depósitos de caída y de oleadas piroclásticas, así como depósitos epiclásticos y depósitos lacustres (Aguirre-Díaz, 1996). Adicionalmente, Norini et al. (2010) fecharon por el método de $\mathrm{U}-\mathrm{Pb}$ en circones un horizonte de caída asociado a la misma secuencia obteniendo una edad de $5.3 \pm 0.31 \mathrm{Ma}$. En el área de estudio esta unidad se encuentra aflorando en el $\mathrm{NO}$ y al $\mathrm{O}$ y cubre parcialmente a las unidades subyacentes, formando lomeríos suaves (Figuras 2 y 5a). La ignimbrita se encuentra muy soldada, con un color ocre al intemperismo, mientras que en fractura fresca se observa un color café rojizo. En muestra de mano se compone de abundantes líticos, cristales de cuarzo, plagioclasa y vidrio. En ocasiones se pueden observar algunos fiammes. Al microscopio se observa una textura eutaxítica con fenocristales de plagioclasa y piroxeno, líticos, pómez y fiammes (Figura 5b).

\section{Ignimbrita Huichapan}

La Ignimbrita Huichapan, asociada a la formación de la caldera homónima, aflora principalmente en la parte NE del área y se distribuye al E y SE (Aguirre-Díaz, 1996) (Figuras 2 y 5c). Se observa formando lomeríos suaves, cubre parcialmente a las lavas del Volcán Ñadó y en ocasiones subyace y en otras sobreyace a los productos del vulcanismo 

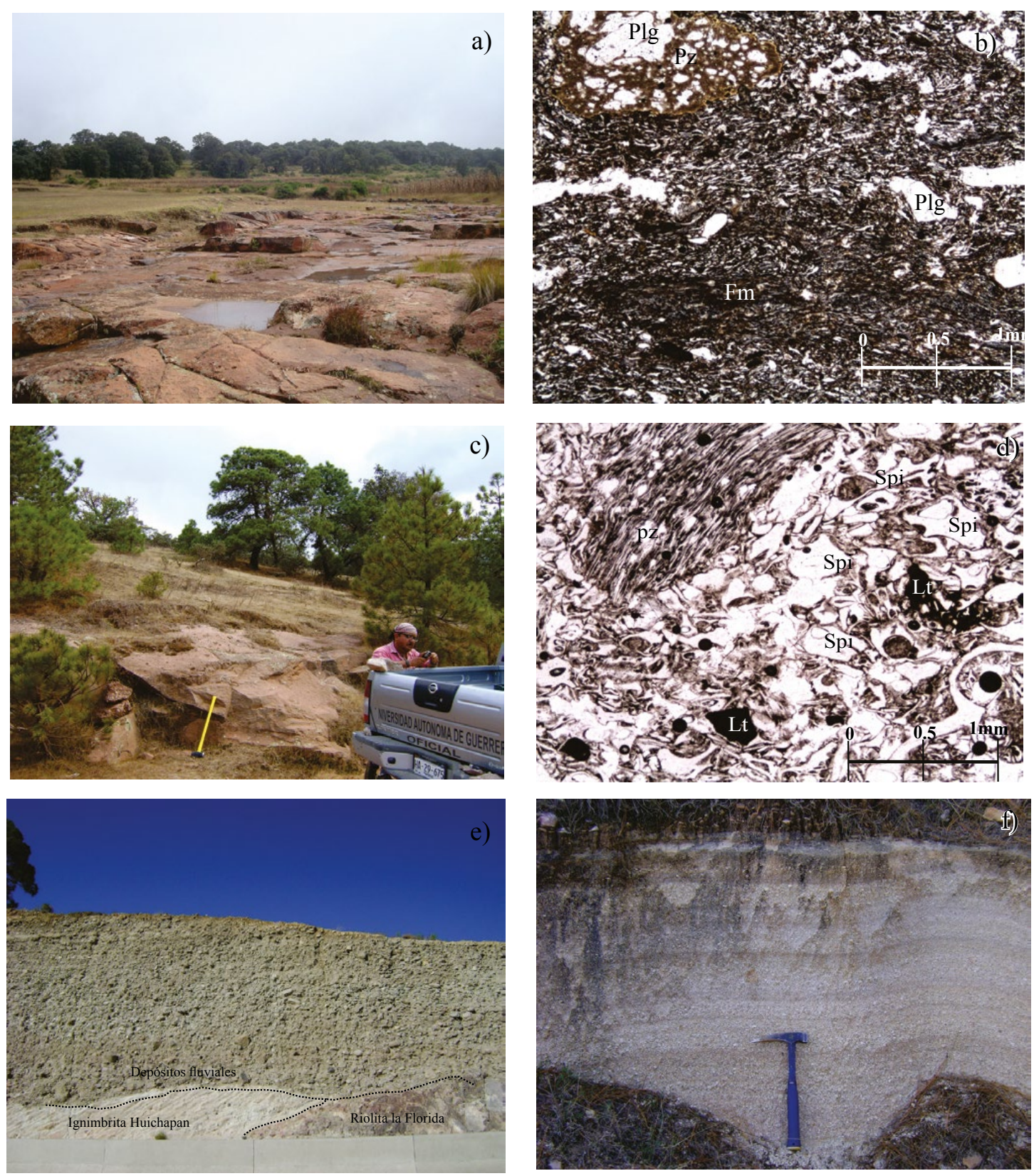

Figura 5. Unidades de la secuencia post-Nadó. a) Fotografía de un afloramiento de la ignimbrita Amealco, localizado al sur del volcán Nadó, que se presenta masivo y de coloración rosada. b) Microfotografía que muestra la textura piroclástica de la ignimbrita Amealco (ÑDO-0949), con vesículas alargadas, fenocristales de plagioclasa (Plg), pómez $(\mathrm{Pz})$ y fiammes $(\mathrm{Fm})$. c) Fotografía de un afloramiento de la ignimbrita Huichapan, con una tonalidad rosa claro y estructura masiva. Este afloramiento se ubica al noreste del volcán Ñadó. d) Microfotografía de la textura piroclástica formada por líticos (Lt), fragmentos de vidrio (Spi), pómez $(\mathrm{Pz})$ y cristales en la ignimbrita Huichapan (ÑDO-0901). e) Fotografía que muestra la relación estratigráfica de la Riolita La Florida sobreyacida por la ignimbrita Huichapan que a su vez subyace a depósitos de flujos de escombros y depósitos fluviales (afloramiento localizado en donde se colectó la muestra Ñdo-932; Figura 2). f) Fotografía de un afloramiento en donde se observa un depósito de caída rico en pómez, localizado sobre la carretera que conduce al poblado de Agostadero. El afloramiento mide $1.70 \mathrm{~m}$ de espesor y está constituido por pómez angulosa de tonalidad gris claro.

máfico (Figura 2). En el poblado La Florida es posible observar la Ignimbrita Huichapan sobre la Riolita La Florida. Sobreyaciendo a éstas se encuentran lahares y depósitos fluviales (Figura 5e). La Ignimbrita Huichapan llega a formar depósitos de espesores de hasta $15 \mathrm{~m}$, los cuales desarrollan estructuras columnares moderadamente soldadas. En muestra de mano se observa una textura piroclástica, presenta un color de intemperismo café rojizo, mientras que en roca sana presenta un color rosa. En la muestra se pueden observar fragmentos líticos y pómez de color oscuro, café, gris y blanco, todos estos embebidos en una matriz de ceniza. Los fragmentos de pómez están principalmente alargados formando fiammes y sus dimensiones van de $2 \mathrm{~mm}$ a $3 \mathrm{~cm}$. En lámina delgada presenta una textura piroclástica o fragmentada. En su mayoría es vidrio (Figura 5d), se observan líticos, cristales de plagioclasa y piroxeno. Los líticos alcanzan un tamaño máximo de $2.5 \mathrm{~mm}$ de longitud; en menor proporción se observan fragmentos de pómez alargados (fiammes) de color café de hasta $3.5 \mathrm{~mm}$ de largo. 


\section{Lahares}

Se describieron algunos afloramientos con depósitos de lahar, principalmente en la parte sur-sureste del área (Figura 2), cubriendo varias de las unidades litológicas descritas, principalmente a las Dacitas Ñadó. Los depósitos de lahar están representados por varias secuencias, probablemente de diferente edad, y afloran con espesores de 15 a $20 \mathrm{~m}$ en la parte sur, mientras que en la zona SE se tienen espesores de hasta $8 \mathrm{~m}$. En los afloramientos de depósitos de lahar de la región sur (Figura 2) se observaron una gran cantidad de fragmentos muy similares a las lavas del volcán Ñadó, con tamaños muy variables que van desde los 5 a $90 \mathrm{~cm}$, inmersos en una matriz arenosa muy consolidada.

\section{Depósito de pómez de caída}

Esta unidad se observó en los poblados de Shaxni, Agostadero y al sur y norte de la Cañada del Gallo. Estos depósitos tienen un espesor total de 2 a $3 \mathrm{~m}$, presentan un color café claro a rosáceo, están conformados por fragmentos subangulosos de pómez, soportados grano a grano, con un tamaño de $0.5 \mathrm{~cm}$ a $6 \mathrm{~cm}$ (Figura 5f). Mineralógicamente la pómez se caracteriza por contener abundante hornblenda, biotita y plagioclasa. El volcán Temascalcingo, localizado al sur de la zona de estudio tiene varios depósitos de caída de pómez, los cuales son muy semejantes mineralógicamente a los observados para este trabajo. Los afloramientos de los depósitos de pómez de caída están muy restringidos en el área de estudio, y por lo tanto no fue posible realizar mapas de isopacas e isopletas. Sin embargo, recientemente Pedrazzi et al. (2018) reportaron una edad ${ }^{40} \mathrm{Ar} /{ }^{39} \mathrm{Ar}$ de $2.13 \pm 0.12 \mathrm{Ma}$ que asocian con la edad de la erupción de la pómez San Mateo, emitida por el volcán Temascalcingo. Además, las isopacas que reportan estos mismos autores, muestran una distribución hacia el N-NE, en cuya dirección se localiza el CVÑ, por lo cual es muy probable que los depósitos de caída pómez descritos en este trabajo provengan del volcán Temascalcingo.

\section{EDAD}

En el área de estudio no existen fechamientos de ninguna de las unidades litológicas aquí descritas, excepto por las reportadas para
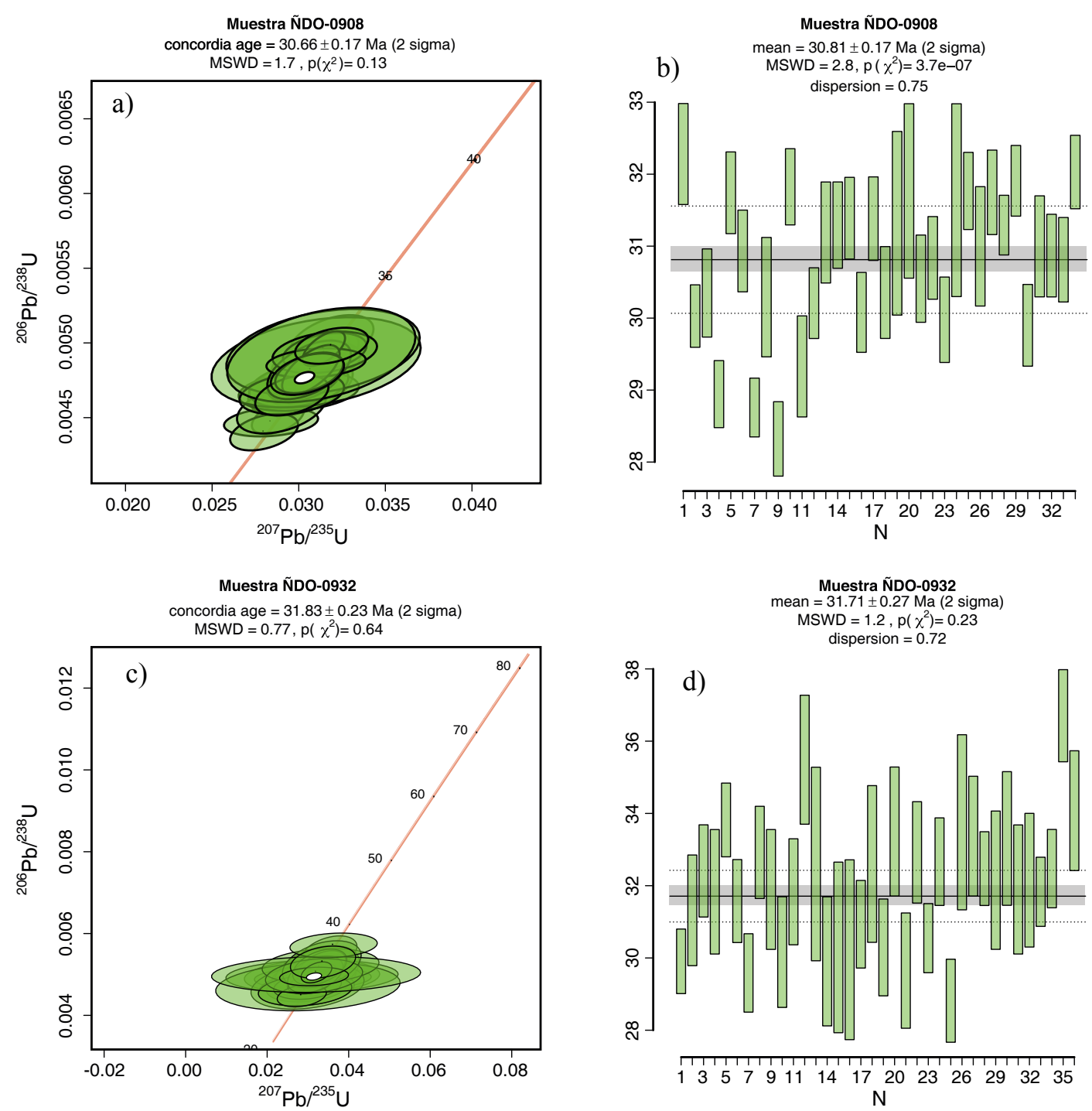

Figura 6. Diagramas de concordia y media ponderada ${ }^{206} \mathrm{~Pb} /{ }^{238} \mathrm{U}$ para la muestra ÑDO- 908 (a y b), NDO- 932 (c y d) que muestran las edades obtenidas en circones de la Riolita La Florida. 


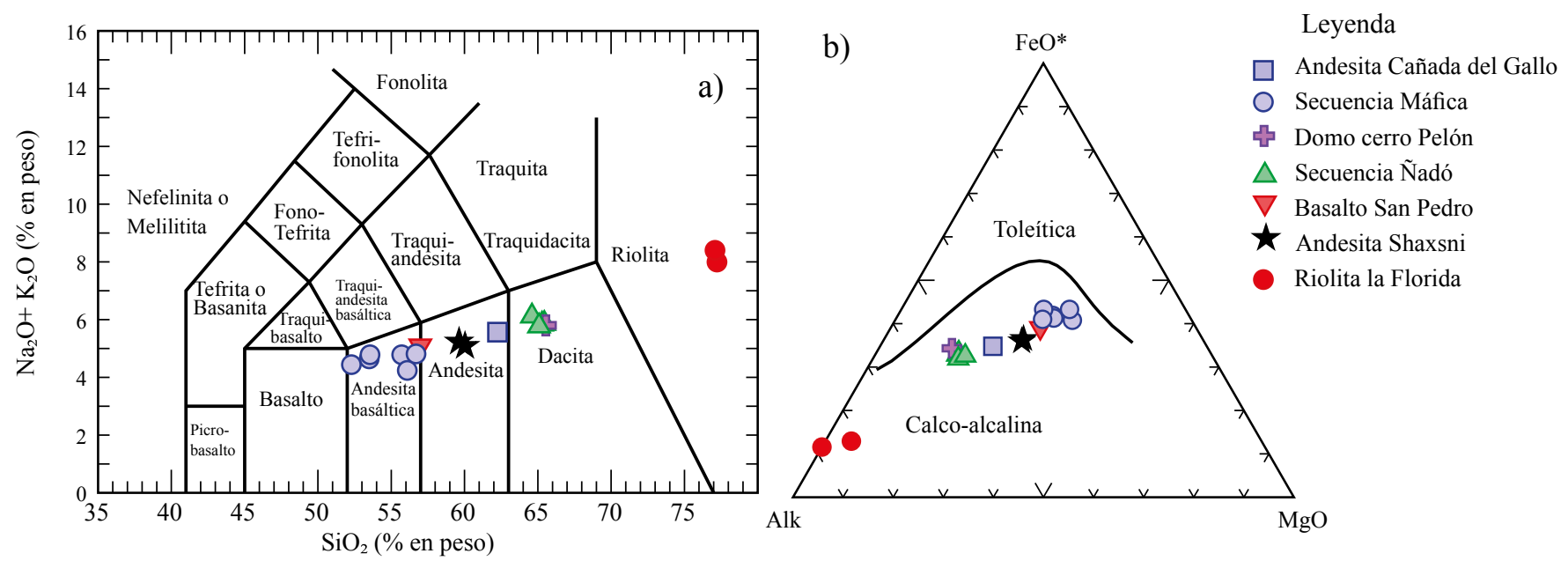

Figura 7. a) Diagrama de álcalis total vs. sílice (Le Bas et al., 1986) para la clasificación química de las unidades litológicas del CVÑ. b) Diagrama AFM en que se observa la clasificación dentro de la serie calco-alcalina para las muestras del CVÑ. Los datos fueron normalizados normalizados al 100\% en base anhidra.

los depósitos piroclásticos pertenecientes a las calderas de Amealco y Huichapan, que se localizan en la parte NO, N y NE del volcán Ñadó.

Dos muestras correspondientes a la Riolita La Florida (ÑDO-908 y ÑDO-932), fueron fechadas por el método de U-Pb (Tabla A2). La mayoría de circones analizados resultaron concordantes (34 de $40 \mathrm{y}$ 36 de 41, respectivamente) en los diagramas de concordia (Figuras 6a y 6 c) y fueron utilizados para calcular las edades medias ponderadas (Figuras $6 \mathrm{~b}$ y $6 \mathrm{~d}$ ). Los promedios de las edades obtenidas de $30.81 \pm 0.17$ y $31.71 \pm 0.27 \mathrm{Ma}$ se interpretan como edades de emplazamiento de la Riolita La Florida. Con base en estos resultados la Riolita La Florida representa las rocas volcánicas más antiguas del área de estudio. Para el volcán Nadó se procesaron dos muestras de lava de composición dacítica, sin embargo, no fue posible encontrar cristales de circón, por lo tanto, no se tienen edades radiométricas para esta estructura. Por posición estratigráfica se puede considerar que el volcán Nadó es más antiguo que $5 \mathrm{Ma}$, ya que sus productos están cubiertos por las ignimbritas de las calderas de Amealco y Huichapan.

\section{GEOQUÍMICA}

\section{Elementos mayores}

Para la clasificación química de las muestras del CVÑ, se utilizó el diagrama de álcalis total $v s$. sílice de Le Bas et al. (1986). Las muestras de la Riolita La Florida varían de 76.1 a 76.4 \% en sílice. Las dacitas del Volcán Nadó y del domo Cerro Pelón muestran un contenido en sílice de 63.9-64.5 \% y 65.1\%, respectivamente. La andesita Shaxni muestra un contenido en sílice de 59.0-59.3 \% y la andesita Cañada de Gallo de $61.5 \%$. El basalto San Pedro contiene $56.2 \%$ de $\mathrm{SiO}_{2}$, mientras que las muestras del vulcanismo máfico varían de 51.6 a $52.26 \%$ de $\mathrm{SiO}_{2}$ (Tabla 1; Figura 7a).

Las rocas del CVÑ pertenecen a la serie calci-alcalina, según Irvine y Baragar (1971), con claras tendencias evolutivas a excepción de las riolitas La Florida, las cuales presentan un elevado contenido de álcalis con respecto a las otras muestras del volcán Ñadó (Figura 7b).

En los diagramas Harker de elementos mayores (Figura 8), los elementos de $\mathrm{MgO}, \mathrm{TiO}_{2}, \mathrm{CaO}, \mathrm{P}_{2} \mathrm{O}_{5}$ y FeO presentan una disminución con respecto al incremento de $\mathrm{SiO}_{2}$, lo cual genera una tendencia negativa, con una variación más pronunciada para $\mathrm{TiO}_{2}$. Por otro lado, los óxidos de $\mathrm{K}_{2} \mathrm{O}$ y $\mathrm{Na}_{2} \mathrm{O}$ presentan un sutil incremento con respecto al aumento del $\mathrm{SiO}_{2}$, marcando una ligera tendencia positiva. Cabe mencionar que el $\mathrm{Al}_{2} \mathrm{O}_{3}$ es el único óxido que no muestra una tendencia definida. Nuevamente para la Riolita La Florida se aprecia una tendencia diferente a la que siguen el resto de las muestras, especialmente en el contenido de $\mathrm{Na}_{2} \mathrm{O}, \mathrm{K}_{2} \mathrm{O}$ y $\mathrm{Al}_{2} \mathrm{O}_{3}$ (Figura 8).

\section{Elementos Traza}

En los diagramas bivariados de elementos traza vs. $\mathrm{SiO}_{2}$ (Figura 9) se observa una tendencia negativa en los elementos $\mathrm{Cr}$, V, Co y ligeramente negativa para el Ni y Zr. En los elementos Sr y Ba se aprecia una ligera tendencia positiva. Resalta el bajo contenido de Ba en la Riolita La Florida, comparado con las demás muestras (Figura 9) a pesar de que son rocas más evolucionadas.

Se utilizó el diagrama normalizado a manto primitivo, usando los datos de Sun y McDonough (1989). En las Figuras 10a y 10b se puede observar el comportamiento de los elementos traza de las rocas del CVÑ, con un ligero enriquecimiento de los elementos LILE con respecto a los HFSE. En dicho diagrama se observan anomalías positivas en $\mathrm{Ba}, \mathrm{K}, \mathrm{Pb}, \mathrm{Sr}$ y anomalías negativas en $\mathrm{Nb}$, Ta, Ti y P. Para el caso de la Riolita La Florida (Figura 10c) se observan anomalías positivas en $\mathrm{Cs}, \mathrm{K}$ y $\mathrm{Pb}$, así como anomalías negativas muy marcadas en $\mathrm{Ba}, \mathrm{Sr}, \mathrm{P}, \mathrm{Eu}$ y Ti.

En el diagrama de REE (Figuras 11a, 11b) normalizado usando valores de condritas de Sun y McDonough (1989) se observa un fuerte enriquecimiento de las LREE con respecto a las HREE. La Riolita La Florida presenta un patrón diferente a las otras muestras del CVÑ (Figura 11c), ya que en general las tierras raras ligeras y pesadas se muestran casi planas y una anomalía negativa muy marcada en Eu.

\section{DISCUSIÓN}

\section{Evolución geológica del CVÑ}

La historia geológica del complejo volcánico Nadó es un ejemplo de la actividad miocénica del CVTM, cuyo origen está relacionado con la subducción oblicua de las placas tectónicas de Cocos y Rivera, para las cuales se han reportado edades en la trinchera de 12.7-16 Ma y $9 \mathrm{Ma}$, respectivamente (Klitgord y Mammerickx, 1982, Urrutia-Fucugauchi y Del Castillo, 1977; Urrutia-Fucugauchi y Böhnel, 1987; Pardo y Suárez, 1993; Pardo y Suárez, 1995). 

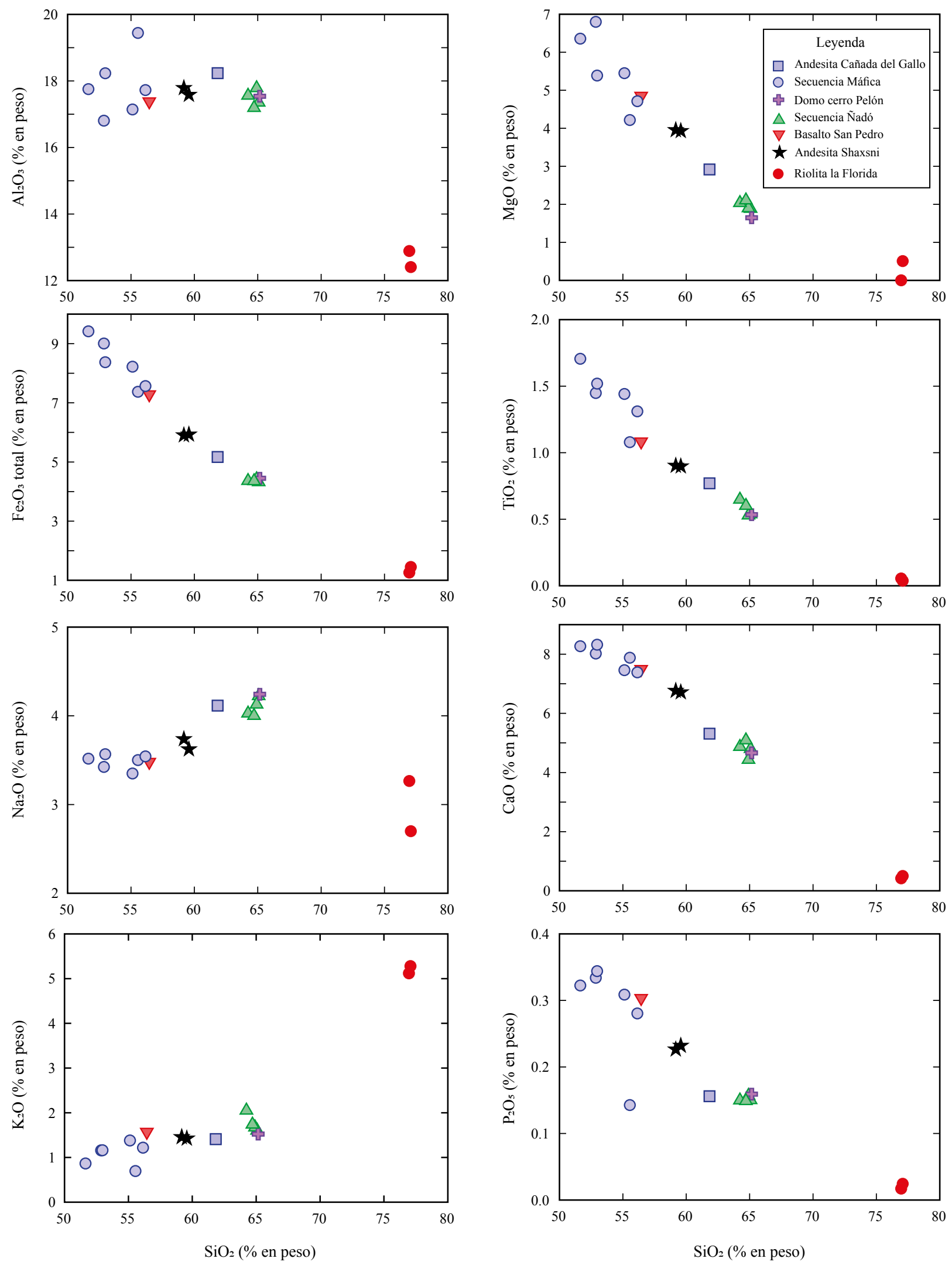

Figura 8. Diagramas de Harker de los elementos mayores $v s . \mathrm{SiO}_{2}(\%$ en peso) para las rocas del CVÑ. Los datos fueron normalizados al $100 \%$ en base anhidra y el Fe total se reporta como $\mathrm{Fe}_{2} \mathrm{O}_{3}$. 

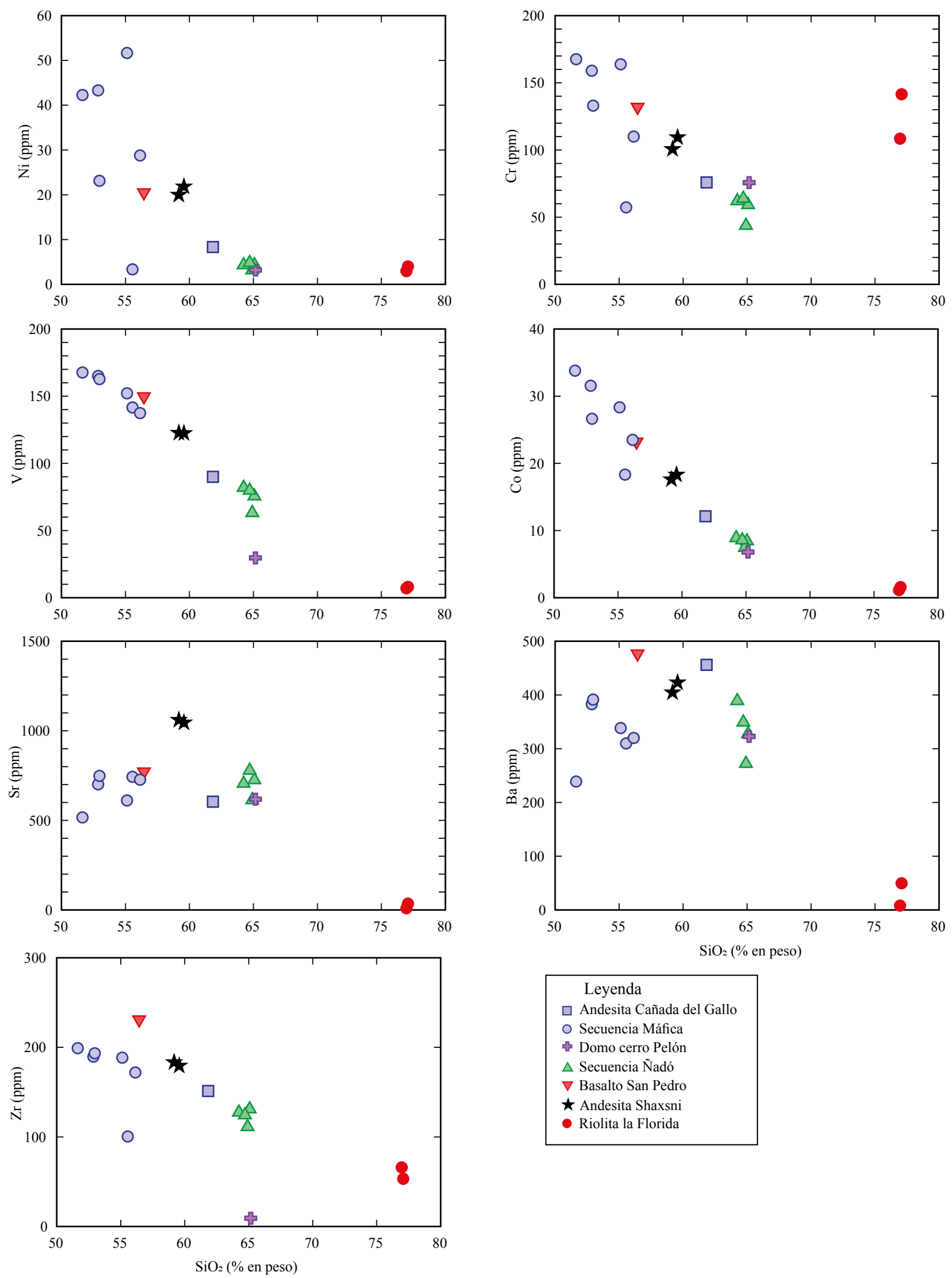

Leyenda

$\square$ Andesita Cañada del Gallo

O Secuencia Máfica

\$ Domo cerro Pelón

$\triangle$ Secuencia Ñadó

$\nabla$ Basalto San Pedro

$\star$ Andesita Shaxsni

- Riolita la Florida

Figura 9. Diagramas bivariados en los que se muestran las tendencias de algunos elementos traza en ppm $v s . \mathrm{SiO}_{2}(\%$ en peso) de rocas del CVÑ. 
Ferrari et al. (1999) documentan que el CVTM se inició como una entidad geológica distintiva en el Mioceno medio y tardío, a causa de una rotación antihoraria del arco magmático que dio origen a la Sierra Madre Occidental (SMO). A partir de este periodo hasta la actualidad y de manera ininterrumpida, se han originado una variedad de rocas que van desde basaltos hasta riolitas, emitidas a través de diversas estructuras (domos, campos monogenéticos, estratovolcanes y calderas) como el estratovolcán Ñadó.

Las etapas de emplazamiento de las rocas del área del volcán Nadó se pueden agrupar en las secuencias 1. pre-Ñadó, 2. Ñadó y 3. postÑadó. La evolución volcanológica que se propone en este trabajo está basada en observaciones y relaciones estratigráficas de campo, ya que no se cuenta con estudios previos ni fechamientos de ninguna de las unidades reconocidas en el área estudiada.

Algunas de las secuencias del área del CVÑ se pueden acomodar en los episodios de evolución del CVTM propuestos por Gómez-Tuena et al. (2005), a excepción de la Riolita La Florida (pre-Ñadó), fechada en este trabajo por el método U-Pb en $30.81 \pm 0.17 \mathrm{Ma}$ y $31.71 \pm 0.27 \mathrm{Ma}$, edades que son mucho más antiguas que las etapas iniciales del vulcanismo en el CVTM, las cuales han sido reportadas entre 16 y $19.5 \mathrm{Ma}$ (Ferrari et al., 2003), $21 \mathrm{Ma}$ (García-Palomo et al., 2000), 19.8-22.8 Ma (Lenhardt et al., 2010), 20.1 Ma (Arce et al., 2013).

Es muy probable que la Riolita La Florida pertenezca a la provincia de la Sierra Madre Occidental (SMO), la cual registró actividad explosiva y efusiva de composición ácida durante el Oligoceno y Mioceno temprano (Ferrari et al., 2005). Edades similares a la Riolita La Florida han sido reportadas para ignimbritas que afloran en el estado de Michoacán, al sur del lago de Chapala (31.8 Ma; Rosas-Elguera et al., 2003; 23.5 Ma, Ferrari et al., 2002). La Riolita La Florida ya había sido emplazada en el área de estudio (Figura 12-1), cuando se originaron el resto de las unidades pre-Nadó (Figura 12-1).
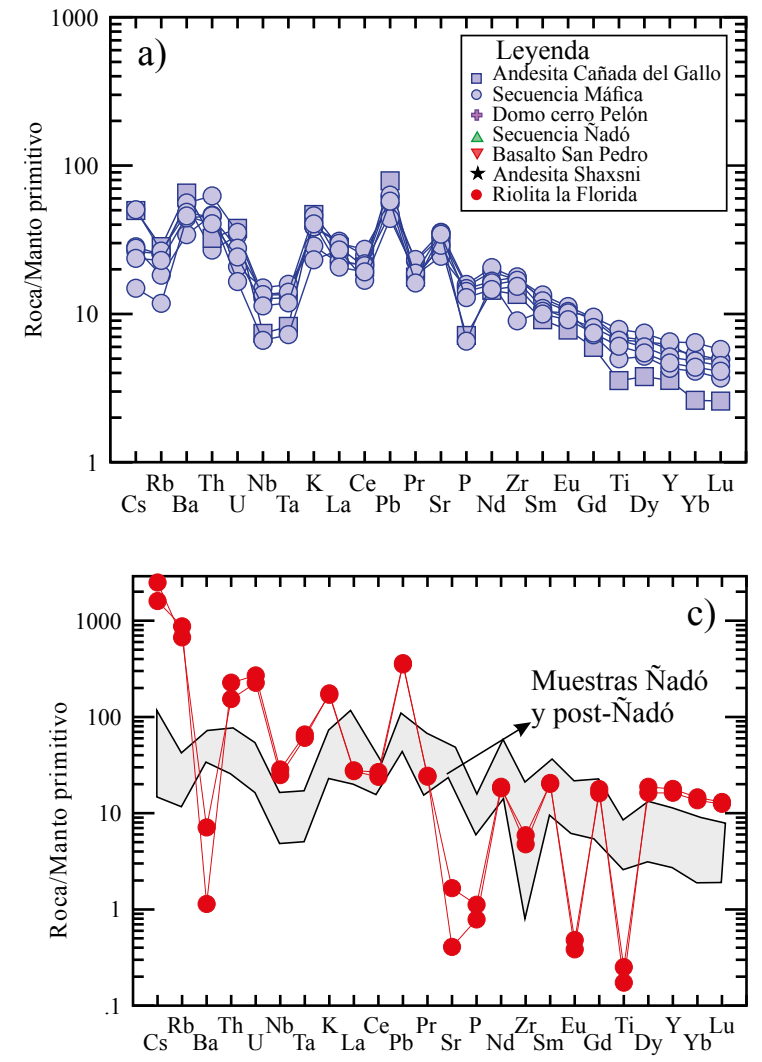

Con base en su posición estratigráfica y grado de erosión (Figura 2), las dacitas del volcán Decandeje (pre-Ñadó) probablemente se emplazaron en el episodio inicial del CVTM (Gómez-Tuena et al., 2005). Posteriormente se originaron las unidades andesita Shaxni, basalto San Pedro y basalto Boti, que se pueden correlacionar con el segundo episodio (pulso máfico) de magmatismo del CVTM que varía de Mioceno tardío a Plioceno (Gómez-Tuena et al., 2005).

Durante el Mioceno tardío inicia la construcción del Volcán Nadó (Figura 12-2) con el emplazamiento de derrames de lavas dacíticas desde una fuente central, seguido por el emplazamiento de domos dacíticos somitales.

La actividad central en el Volcán Ñadó fue acompañada por un vulcanismo máfico, monogenético, con el emplazamiento de conos de escoria que, de acuerdo a sus relaciones estratigráficas, se formaron en distintos periodos, tanto durante como después de la actividad del volcanismo central dacítico, así como antes y después del emplazamiento de la ignimbrita Huichapan.

Finalmente, la actividad del CVN termina con el emplazamiento de las Andesitas Cañada de Gallo (Figura 12-3), previo a la formación de las calderas de Amealco y Huichapan (4.7-5.3 Ma y 3.4-4.7 Ma respectivamente; Aguirre-Díaz et al., 1997; Aguirre-Díaz y McDowell, 2000; Norini et al., 2010). Por último, los depósitos de pómez de caída, que afloran en diversas localidades del área, representan una de las rocas volcánicas más jóvenes del área y debido a los espesores medidos, las dimensiones de los fragmentos y los mapas de isopacas reportados por Pedrazzi et al. (2018), es posible que su fuente de emisión sea el volcán Temascalcingo, localizado al sur de la zona de estudio, dentro del graben de Acambay (Roldán-Quintana et al., 2011), cuyo depósito de caída ha sido fechado por el método ${ }^{40} \mathrm{Ar} /{ }^{39} \mathrm{Ar}$ en $2.13 \pm 0.12 \mathrm{Ma}$ (Pedrazzi et al., 2018). Los depósitos de lahares descritos en la parte sur de la estructura principal, probablemente se generaron en distintos tiempos

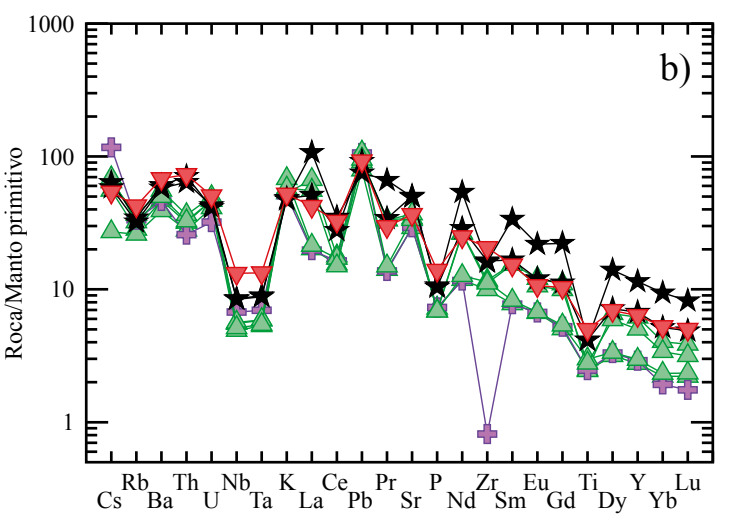

Figura 10. Diagramas multielementales normalizados a manto primitivo utilizando los valores de Sun y McDonough (1989). a) Unidades de la secuencia post-Ñadó; b) Unidades de la secuencia pre-Ñadó y Nadó; c) Riolita La Florida de la secuencia pre-Ñadó comparada con las unidades Ñadó y post-Ñadó. 

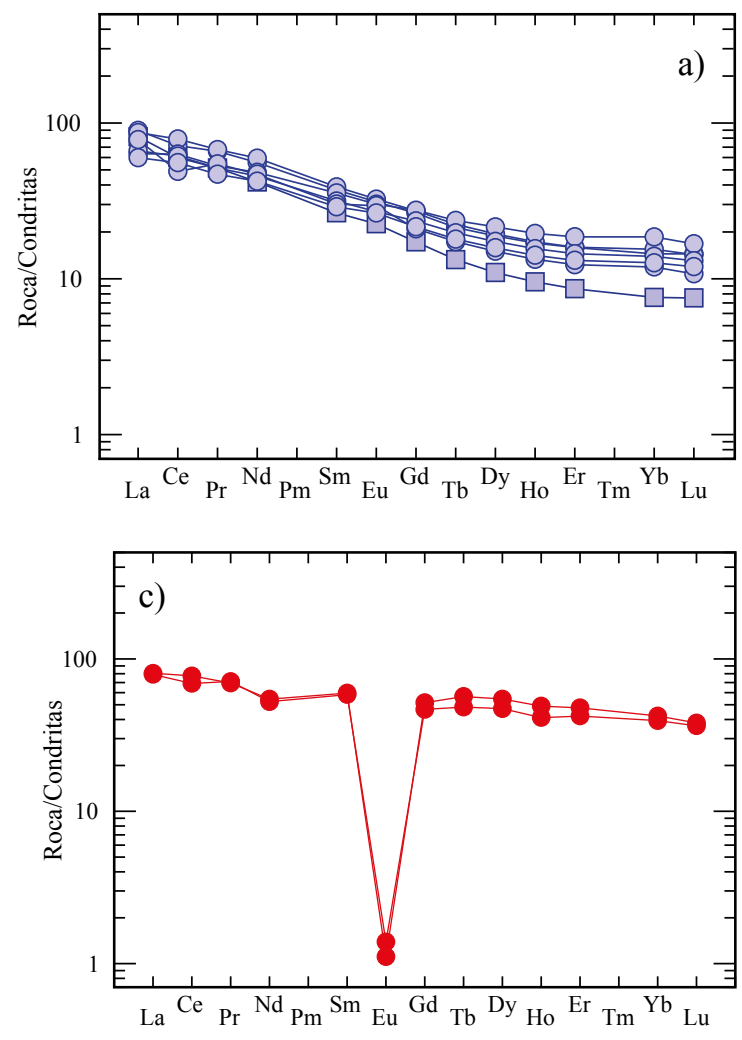

y en ausencia de actividad volcánica. Además, dado que su morfología es relativamente suave y con pocos rasgos de erosión, podrían ser uno de los depósitos más jóvenes o contemporáneos con la pómez de caída que aflora en el área de estudio.

\section{Petrogénesis}

Las rocas del complejo volcánico Ñadó, excepto la Riolita La Florida, dadas las características geoquímicas como el enriquecimiento de elementos LILE con respecto a los HFSE y anomalías negativas de $\mathrm{Nb}, \mathrm{Ta}, \mathrm{P}$ y Ti, así como anomalías positivas, no tan marcadas de $\mathrm{Ba}$, $\mathrm{K}, \mathrm{Pb}$ y Sr (Figura 10) sugieren un ambiente de subducción para los magmas que dieron origen a estas rocas (Rollinson, 1993). En este sentido, dichas anomalías sugieren diferente grado en la contribución del slab cuando se compara con otros volcanes del CVTM (e.g. Volcán de Colima y Popocatépetl) los cuales presentan anomalías positivas y negativas más claras en los elementos ya mencionados. Las relaciones $\mathrm{de} \mathrm{Ba} / \mathrm{Nb}$ han sido utilizados como un proxy para medir de manera relativa la influencia del slab en la generación de magmas en zonas de subducción (Pearce et al., 2005). Como se aprecia en la Figura 13a, las muestras del CVÑ tienen valores bajos en la relación $\mathrm{Ba} / \mathrm{Nb}$ comparado con el Nevado de Toluca, e incluso comparado con rocas de la Formación Tepoztlán también del Mioceno. Es decir que los magmas del CVÑ presentan una firma más débil de subducción, probablemente debido a que se localiza a una distancia mayor (aproximadamente 400 $\mathrm{km}$ ) de la trinchera, comparado con Tepoztlán y el volcán Nevado de Toluca, ambos ubicados en el frente volcánico (ubicados aproximadamente a $300 \mathrm{~km}$ desde la trinchera).

Una variación similar se observa en Centroamérica, en donde las rocas del frente volcánico y los volcanes tras-arco presentan diferentes relaciones de $\mathrm{Ba} / \mathrm{La}$ vs. U/Th (Figura 13b), indicadores de la contribución del slab y el aporte de sedimentos (Carr et al., 1990; Balzer et al., 1996; Patino et al., 2000). Para el arco de Centroamérica se observa

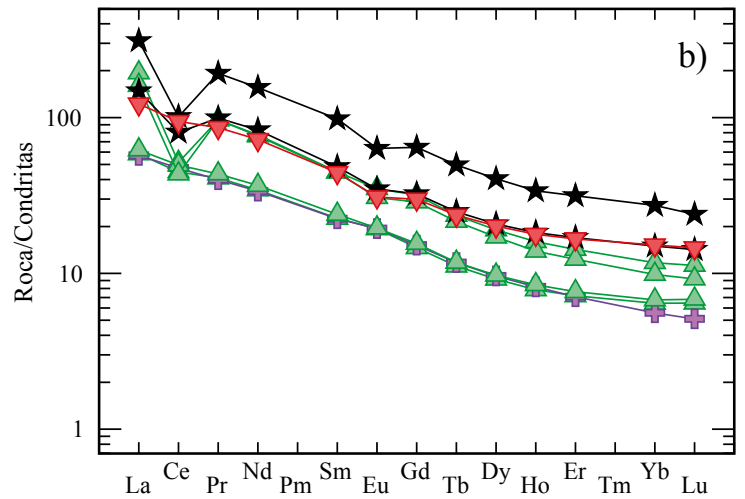

\begin{tabular}{|l|l|}
\hline Leyenda \\
$\square$ Andesita Cañada del Gallo \\
$\bigcirc$ Secuencia Máfica \\
$\lessgtr$ Domo cerro Pelón \\
$\triangle$ Secuencia Ñadó \\
$\nabla$ Basalto San Pedro \\
$\star$ Andesita Shaxsni \\
Riolita la Florida
\end{tabular}

Figura 11. Diagrama de tierras raras normalizados a condritas utilizando los valores de Sun y Mc Donough, 1989. a) Unidades de la secuencia post-Ñadó; b) Unidades de la secuencia pre-Ñadó y Ñadó; c) Riolita La Florida de la secuencia pre-Ñadó.

que los volcanes más alejados de la trinchera (tras-arco de Guatemala y Honduras) presentan valores más bajos de las relaciones $\mathrm{Ba} / \mathrm{La} \mathrm{y} \mathrm{U/Th}$, lo que sugiere un aporte menor de sedimentos (Figura 13b). Usando estas mismas relaciones, las lavas del CVÑ muestran un cierto grado de dispersión (Figura 13b), lo que puede sugerir distintos grados de aporte de sedimentos.

Para mejor identificar la contribución de fluidos acuosos o de fundidos de sedimentos como agentes que intervinieron en la generación de los magmas que dieron origen a las rocas del CVÑ, también se utilizaron las relaciones $\mathrm{Ba} / \mathrm{La} v s$. Th/Nb (Figura 13c) (Pearce et al., 2005; Hanyu et al., 2006). En esta gráfica se aprecia que las rocas del CVÑ muestran valores bajos en ambas relaciones, lo cual nuevamente sugiere que sus magmas tuvieron poco aporte de ambos agentes metasomáticos (fundidos de sedimentos y fluidos acuosos). En la misma gráfica se comparan a las rocas del Volcán Nadó con ejemplos típicos de la literatura de magmas enriquecidos en sedimentos (Antillas Menores) y otros con importante influencia de fluidos del slab (Izu-Marianas). Así mismo se comparan con rocas de la Formación Tepoztlán y Nevado de Toluca, en donde se aprecia que Tepoztlán presenta valores similares al CVÑ, mientras que el Nevado de Toluca (Pleistoceno-Holoceno; García-Palomo et al., 2000; Arce et al., 2003; Torres-Orozco et al., 2012) presenta valores altos en ambas relaciones. Esto último podría explicarse por la diferencia de edades, mientras Tepoztlán y CVÑ representan tal vez las primeras manifestaciones del vulcanismo relacionado al CVTM (Mioceno temprano), en donde los primeros fundidos probablemente tuvieron poca influencia del slab, y con el paso del tiempo los fluidos y fundidos modificaron la región de generación de magmas por debajo del CVTM.

El bajo contenido de Ba en la dacita Ñadó (272-388 ppm) y mucho más bajo en la Riolita La Florida (7-49 ppm) no es común, ya que el contenido de este elemento, para rocas más evolucionadas debería incrementar, sin embargo es parecido a riolitas de edad similar des- 

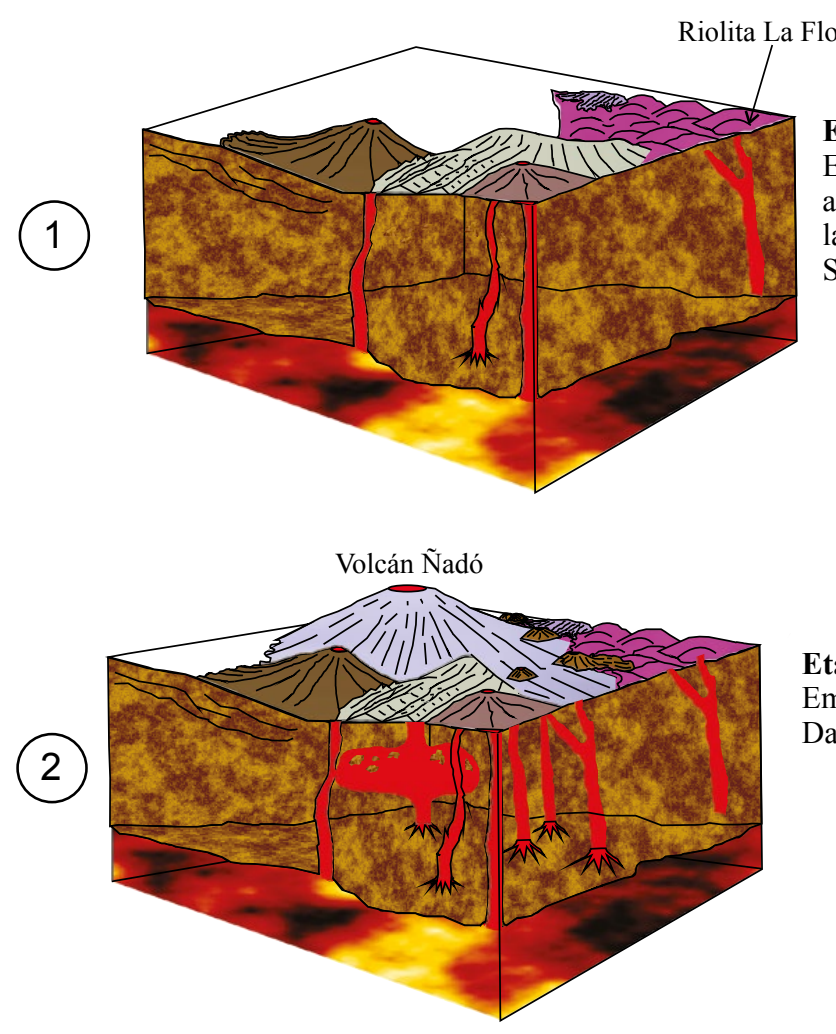

Etapa Pre-Ñadó:

Emplazamiento de la unidad más

antigua Riolita La Florida. Seguido por

lavas Decandeje, Andesita Shaxni, basalto

San Pedro y Basalto Boti.

\section{Etapa Nadó:}

Emplazamiento Dacita Ñadó y

Dacita Cerro Pelón y vulcanismo máfico.

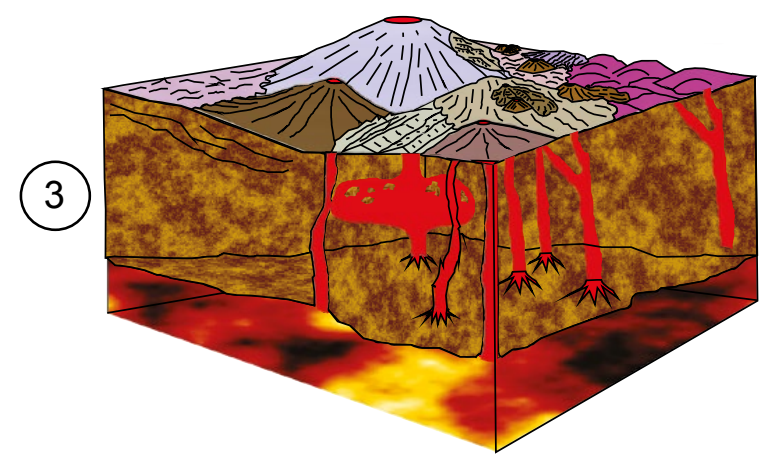

Etapa Post- Nadó:

Emplazamiento de la Andesita

Cañada del Gallo, Ignimbrita Amealco, Ignimbrita Huichapan, vulcanismo máfico y Lahares.

Figura 12. Modelo evolutivo del complejo volcánico Ñadó. 1. Emplazamiento de la secuencia pre-Ñadó. 2. Edificación de la secuencia Ñadó. 3. Emplazamiento de la secuencia post-Ñadó.

critas en la Sierra Madre Occidental, con fenocristales de fayalita y/o ferroaugita, asociados a eventos de extension intraplaca (Ferrari et al., 2018). Un caso similar ha sido documentado en el campo volcánico de los Mono-cráteres, en el este de California, cuyas lavas dacíticas presentan bajo contenido de $\mathrm{Ba}(300 \mathrm{ppm})$, el cual posiblemente es derivado de una fuente cortical que contiene feldespato potásico residual (Kelleher y Cameron, 1990). Esto mismo podría explicar los contenidos relativamente bajos de Ba para la dacita Ñadó. Sin embargo, la Riolita La Florida adicionalmente presenta bajas concentraciones de Sr y Eu (Figura 10c), probablemente debido a procesos de cristalización fraccionada de plagioclasa, ya que estos elementos son compatibles con esta fase mineral (Rollinson, 1993). Respecto al diagrama de tierras raras (Figura 11c), en muestras de la Riolita La Florida se observa un comportamiento totalmente diferente al del resto de las unidades del CVÑ. En general las LREE y HREE se observan con poca pendiente, lo cual puede deberse a la presencia de minerales accesorios como monacita y xenotima, los cuales fueron observados en el microscopio electrónico en muestras de la Riolita La Florida (Montero, 2012).

Con base en las edades de $30.81 \pm 0.17$ Ma y $31.71 \pm 0.27$ Ma de la Riolita La Florida, se puede postular que su génesis se debió a la subducción de la placa Farallón (Ferrari et al., 1999), que generó a todas las rocas de la Sierra Madre Occidental con edades similares. Sin embargo, en este punto es difícil sugerir o proponer una génesis particular, ya que los posibles mecanismos que originan este tipo de rocas es muy amplia, entre ellas podrían estar los dos procesos extremos que se han propuesto para la generación de magmas riolíticos de la Sierra Madre Occidental: fusión parcial de la corteza (Hupper y Sparks, 1988; Ruiz et al., 1988, 1990; Albrecht y Goldsteins, 2000; Ferrari et al., 2002) y cristalización fraccionada de un magma primario (Cameron y Hanson, 1982; Cameron y Cameron, 1985; Cameron et al., 1980a, Cameron et al., 1980b; Cameron y Robinson, 1990 ; Wark, 1991; Smith et al., 1996), aunque también ambos mecanismos han generado polémica. 

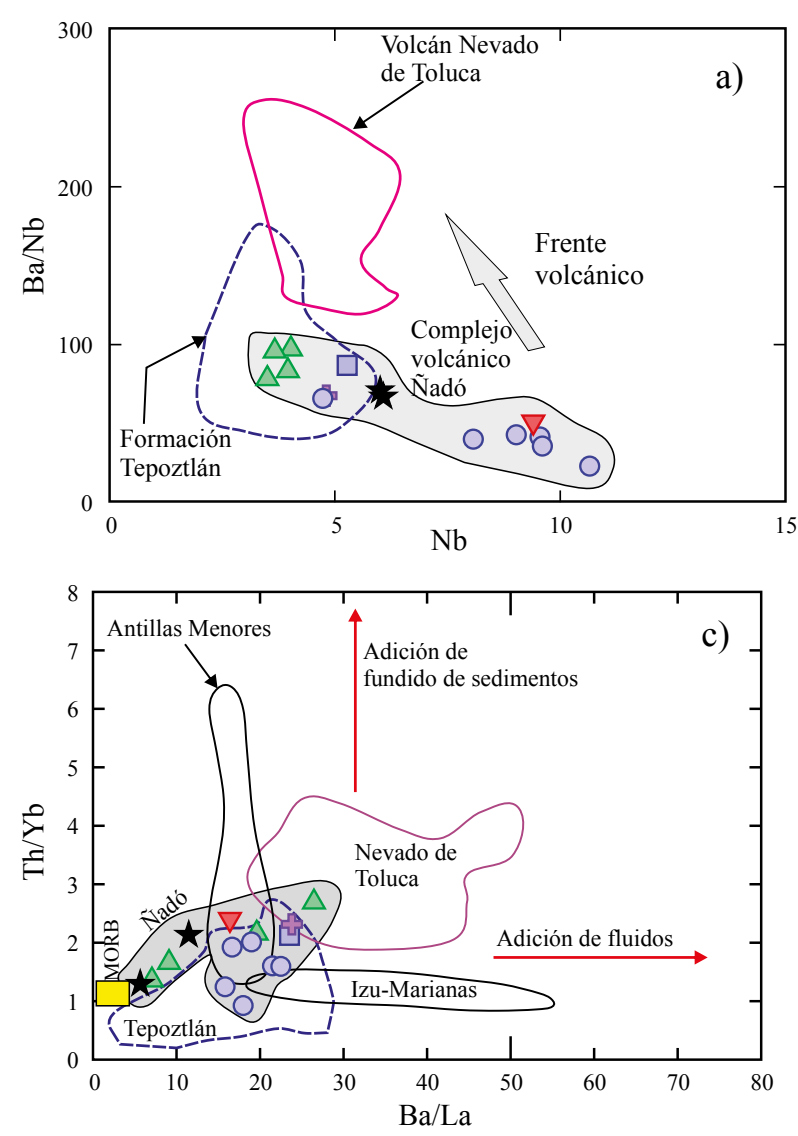

\section{Mecanismo petrológico dominante}

De manera general los magmas pueden experimentar procesos diversos de evolución (e.g., fusión parcial, cristalización fraccionada, asimilación cortical, asimilación-cristalización fraccionada y mezcla de magmas). Los elementos $\mathrm{K}, \mathrm{Rb}, \mathrm{Zr}$ y Nb son altamente incompatibles y cuando se utilizan las relaciones $\mathrm{K} / \mathrm{Rb}$ y $\mathrm{Zr} / \mathrm{Nb}$ vs. $\mathrm{SiO}_{2}$, éstos se mantienen constantes durante un proceso de cristalización fraccionada, excepto en líquidos extremadamente evolucionados (Hart y Allegre, 1980; Albarede, 1995).

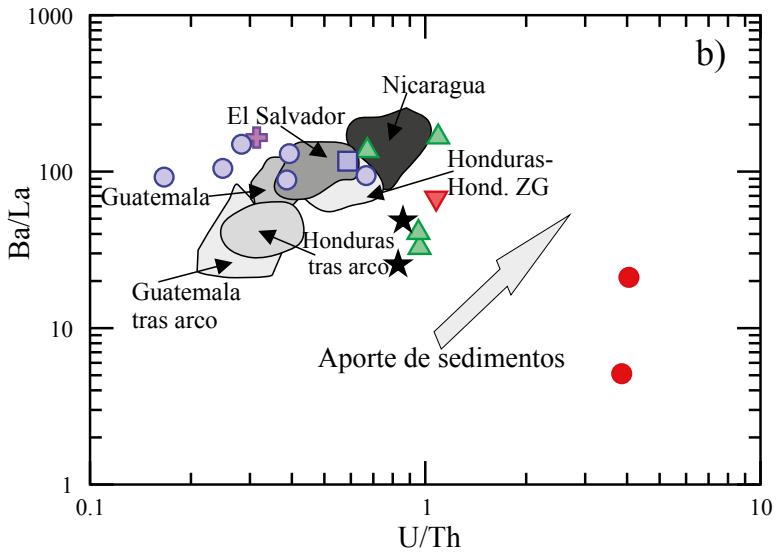

Figura 13. a) Diagrama bivariado de $\mathrm{Ba} / \mathrm{Nb} v s$. $\mathrm{Nb}$ de rocas del CVÑ comparado con muestras de la Formación Tepoztlán (Mioceno) (datos tomados de TorresAlvarado et al., 2016) y Nevado de Toluca (datos tomados de Torres-Orozco, 2012). b) Diagrama bivariado de Ba/La vs. U/Th para las muestras del CVÑ y su comparación con volcanes de Centroamérica. Los campos en gris fueron tomados de Patino et al. (2000) y corresponden a los complejos volcánicos de Centroamérica: Honduras: complejo Zacate Grande (ZG); un complejo localizado a $17 \mathrm{~km}$ detrás del frente volcánico. c) Diagrama bivariado de $\mathrm{Th} / \mathrm{Yb} v s$. Ba/La para las muestras del CVÑ y su comparación con otras áreas volcánicas: Nevado de Toluca (datos de Torres-Orozco, 2012), Formación Tepoztlán (datos tomados de Torres-Alvarado et al., 2016), así como los campos de las Antillas Menores, Izu-Marianas y datos del MORB (retomados de Hanyu et al., 2006).

De acuerdo con las relaciones de $\mathrm{SiO}_{2}$ vs. $\mathrm{Zr} / \mathrm{Nb}$ y K/Rb (Figura 14) de muestras del complejo volcánico Nadó, el mecanismo o el proceso de evolución dominante parece ser el de asimilación-cristalización fraccionada (AFC), a excepción de la Riolita La Florida y la muestra del domo Cerro Pelón, que parecen haber sufrido un proceso de cristalización fraccionada. El proceso de AFC consiste en la cristalización fraccionada de un grupo de minerales a partir de un magma primario, acoplada con la asimilación de la corteza (Velasco-Tapia, 2003).
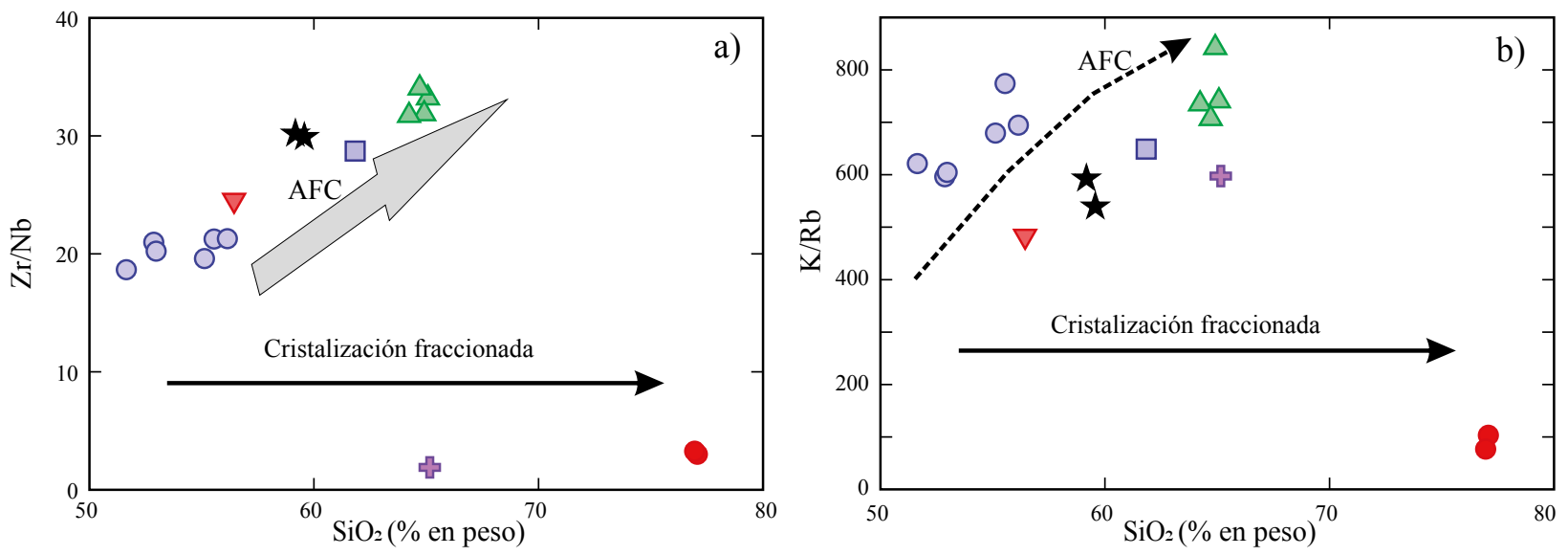

Figura 14. a) Diagrama Bivariado de $\mathrm{Zr} / \mathrm{Nb}$ vs. $\mathrm{SiO}_{2}$ de las muestras del CVÑ con una tendencia positiva que sugiere un proceso de evolución por asimilacióncristalización fraccionada (AFC). b) Diagrama de variación que muestra elementos incompatibles $(\mathrm{K} / \mathrm{Rb}) v s$. $\mathrm{SiO}_{2}$, para las rocas del complejo volcánico Nadó, cuya tendencia también sugiere un proceso de evolución de AFC. Los cocientes $\mathrm{Zr} / \mathrm{Nb}$ y $\mathrm{K} / \mathrm{Rb}$ fueron seleccionados siguiendo los principios teóricos de Hart y Allegre (1980), así como Albarede (1995). 
Particularmente este proceso puede ocurrir en lugares donde existe un gran espesor de corteza, por ejemplo, en bordes continentales activos o en áreas de intraplaca (López-Ruiz, 1994).

\section{CONCLUSIONES}

En este trabajo se reconocieron 11 unidades litológicas en el complejo volcánico Nadó, las cuales se agruparon en tres secuencias: 1. pre-Ñadó, 2. Ñadó y 3. post-Ñadó de acuerdo con su posición estratigráfica. En esta región fueron documentadas varias etapas de evolución del CVTM, así como una etapa de formación de la Sierra Madre Occidental, representado por vulcanismo desde el Oligoceno hasta el presente.

Por primera vez se reportan para esta área edades del Oligoceno obtenidas en riolitas por el método U-Pb en circones en $30.81 \pm 0.17 \mathrm{Ma}$ y $31.71 \pm 0.27 \mathrm{Ma}$, las cuales han sido interpretadas como parte de la Sierra Madre Occidental, por lo que se reporta una localidad nueva que documenta la transición entre la SMO y el CVTM.

Los datos geoquímicos reportados en este trabajo son típicos de magmas generados en un ambiente de subducción, en las tierras raras se observó un enriquecimiento de LREE con respecto a las HREE, mientras que la Riolita La Florida presenta la típica forma de "gaviota", que sugiere una génesis totalmente diferente al resto de las rocas.

Existen argumentos a favor de diferentes contribuciones de sedimentos en las rocas del Mioceno para el CVTM. Los datos geoquímicos del CVÑ indican una variación en la contribución de sedimentos y fluidos, que se puede relacionar a la distancia respecto a la trinchera como ha sido documentado en otros arcos volcánicos clásicos en el mundo, o tal vez a la edad de las rocas del CVÑ, que podrían corresponder con la etapa inicial de vulcanismo en la FVTM.

Por medio de diagramas de variación de $\mathrm{K} / \mathrm{Rb}$ y $\mathrm{Zr} / \mathrm{Nb}$ vs. $\mathrm{SiO}_{2}$ se determinó que posiblemente el mecanismo dominante fue el de AFC, a excepción de la Riolita La Florida y la dacita del Domo cerro Pelón, dominadas por la cristalización fraccionada.

\section{MATERIAL SUPLEMENTARIO}

Las Tablas A1 y A2 están disponibles en el portal web www.rmcg. unam.mx , en la tabla de contenido de este número.

\section{AGRADECIMIENTOS}

Los autores agradecen la beca otorgada por el Instituto de Geología de la Universidad Nacional Autónoma de México (UNAM) a los estudiantes de licenciatura Jesús Cabrera Román y Francisco Javier Castro Segura y la beca otorgada a través del proyecto de fortalecimiento del cuerpo académico de Geociencias. Las facilidades otorgadas por el Laboratorio de Molienda y Separación de Minerales del Insituto de Geología, UNAM, a cargo de la M.C. Consuelo Macías Romo, los análisis de Fluorescencia de Rayos X realizados por la Quim. Patricia Girón García y de elementos traza a través del método de ICP-MS realizados por la M.C. Ofelia Pérez Arvizu en el Laboratorio de Estudios isotópicos del Centro de Geociencias, UNAM. Los fechamientos de U-Pb en circones fueron realizados por los Drs. Carlos Ortega y Luigi Solari en el Laboratorio de Estudios Isotópicos del del Centro de Geociencias, UNAM. Los autores agradecen a Dr. Matteo Roverato, un revisor anónimo, los editores Dra. Lucía Capra y Dr. Peter Schaaf, quienes con sus comentarios mejoraron este trabajo.

\section{REFERENCIAS}

Aguirre-Díaz, G., 1996, Volcanic stratigraphy of the Amealco caldera and vicinity, central Mexican Volcanic Belt: Revista Mexicana de Ciencias Geológicas, 13(1), 10-35.

Aguirre-Díaz, G., 2001, Calderas of the central Mexican Volcanic Belt, Reunión anual de la American Geophysical Union, Eos Transactions American Geophysical Union, 82(47), Fall Meeting Suppl., Abstract. V32D-1020, p. F1350.

Aguirre-Díaz, G., López-Martínez, M., 2001, Evolución geológica de la caldera de Huichapan, Hidalgo, en base a nuevas edades ${ }^{39} \mathrm{Ar} /{ }^{40} \mathrm{Ar}$, Geos, 21, 320-321

Aguirre-Díaz, G., McDowell, F., 2000, Volcanic evolution of the Amealco caldera, central Mexico, en: Delgado-Granados H., Stock J., Aguirre-Díaz G., (eds.), Cenozoic tectonics and volcanism of Mexico: Boulder, CO, Geological Society of America, Special Paper, 334, 167-178.

Aguirre-Díaz, G., Nelson, S., Ferrari, L., López, M., 1997, Ignimbrites of the central Mexican Volcanic Belt, Amealco and Huichapan calderas (Queretaro-Hidalgo), en: Aguirre-Díaz, G., Aranda-Gomez J., CarrascoNúñez, G., Ferrari, L., (eds.), Magmatism and tectonics in the central and northwestern Mexico- a selection of the 1997 IAVCEI General Assembly excursions: México, DF, Universidad Nacional Autónoma de México, Instituto de Geología, Excursión 1, 1-39.

Alaniz-Álvarez, S., Nieto-Samaniego, A., 2005, El sistema de fallas Taxco-San Miguel de Allende y la Faja Volcánica Transmexicana, dos fronteras tectónicas del centro de México activas durante el Cenozoico: Boletín de la Sociedad Geológica Mexicana, LVII (1), 65-82.

Albarede, F., 1995, Introducction to Geochemical Modeling: N.Y, USA, Cambridge University Press, $543 \mathrm{pp}$.

Albrecht, A., Goldstein, S.L., 2000, Effects of basement composition and age on silicic magmas across an accreted terrane-Precambian crust boundary, Sierra Madre Occidental, Mexico: Journal of South American Earth Sciences, 13, 255-273.

Arce, J.L., Macías, J.L., Vázquez-Selem, L., 2003, The 10.5 ka plinian eruption of Nevado de Toluca volcano, (México: Stratigraphy and hazard implications: Bulletin of the Geological Society of America, 115; 2, 230-248.

Arce, J.L., Layer, P.W., Morales-Casique, E., Benowitz, J.A., Rangel, E., Escolero, O., 2013, New constraints on the subsurface geology of the Mexico City Basin: The San Lorenzo Tezonco deep well, on basis on ${ }^{40} \mathrm{Ar} /{ }^{39} \mathrm{Ar}$ geochronology and whole- rock chemistry: Journal of Volcanology and Geothermal Research, 266, 34-49.

Balzer, V., Plank, T., Carr, M.J., 1996, Sediment recycling through time in Nicaragua: AGU Fall Meeting V21A-02

Cameron, K.L., Cameron, M., 1985, Rare earth elements, ${ }^{87} \mathrm{Sr} /{ }^{86} \mathrm{Sr}$, and ${ }^{143} \mathrm{Nd} /{ }^{144} \mathrm{Nd}$ compositions of Cenozoic orogenic dacites from Baja California, northwestern Mexico, and adjacent West Texas; evidence for the predominance of a subcrustal component: Contributions to Mineralogy and Petrology, 91, 1-11.

Cameron, K.L., Hanson G.N., 1982, Rare earth element evidence concerning the origin of voluminous mid-Tertiary rhyolitic ignimbrites and related volcanic rocks, SMO, Chihuahua, Mexico: Geochimica et Cosmochimica Acta, 46, 1489-1503.

Cameron, K.L., Robinson, J.V., 1990, Nd-Sr isotopic compositions of lower crustal xenoliths-evidence for the origin of mid-Tertiary felsic volcanics in Mexico: Comment: Contributions to Mineralogy and Petrology, 104, 609-618.

Cameron, K.L., Cameron, M., Bagby, W.C., Moll, E.J., Drake, R.E., 1980a, Petrologic characteristics of mid-Tertiary volcanic suites, Chihuahua: Geology, 8, 87-91.

Cameron, M., Bagby, W.C., Cameron, K.L., 1980b, Petrogenesis of voluminous mid-Tertiary ignimbrites of the Sierra Madre Occidental: Contributions to Mineralogy and Petrology, 74, 271-284.

Cantagrel, J., Robin, C., 1979, K-Ar dating on eastern Mexican Volcanic rocksrelations between the andesitic and the alkaline provinces: Journal of Volcanology and Geothermal Research, 5, 99-114.

Carr, M.J. Feigenson, M.D., Bennett, E.A., 1990, Incompatible element and isotopic evidence for tectonic control of source mixing and melt extraction along the Central American arc: Contributions to Mineralogy and Petrology, 105, 369-380. 
Carrasco-Núñez, G., Milán, M., Verma, P., 1989, Geología del volcán Zamorano, Estado de Querétaro: Revista Mexicana de Ciencias Geológicas, 8, 194-201.

Demant, A., 1978, Características del Eje Neovolcánico Transmexicano y sus problemas de interpretación: Universidad Nacional Autónoma de México, Revista Instituto de Geología, 2, 172-187.

Demant, A., 1981, Interpretación geodinámica del volcanismo del Eje Neovolcánico Transmexicano: Universidad Nacional Autónoma de México, Revista Instituto de Geología, 5, 217-222.

Ferrari, L., 2000, Avances del conocimiento de la Faja Volcánica Transmexicana: Boletín de la Sociedad Geológica Mexicana, LIII, 84-92.

Ferrari, L., López-Martínez, M., Aguirre-Díaz, G., Carrasco-Nuñez, G., 1999, Space-time patterns of Cenozoic arc volcanism in central México: from the Sierra Madre Occidental to the Mexican volcanic belt: Geology, v. 27, 303-306 pp.

Ferrari, L., López-Martinez, M., Rosas-Elguera, J., 2002, Ignimbrite flareup and deformation in the southern Sierra Madre Occidental, western Mexicoimplications for the late subduction history of the Farallon Plate: Tectonics, 21, 10.1029/2001TC001302.

Ferrari, L., Lopez-Martinez, M., González-Cervantes, N., Jacobo-Albarrán, J., Hernández-Bernal, M. S., 2003, Volcanic record and age of formation of the Mexico City basin, en: Reunión Annual 2003, Resúmenes: GEOS, 23(2), $120 \mathrm{pp}$.

Ferrari, L., Valencia-Moreno, M., Scott, B., 2005, Magmatismo y tectónica de la Sierra Madre Occidental y su relación con la evolución de la margen occidental de Norteamérica: Boletín de la Sociedad Geológica Mexicana, Volumen Conmemorativo del Centenario, Temas Selectos de la Geología Mexicana, LVII (3), 343-378.

Ferrari, L., Orozco-Esquivel, T., Scott, B., López-Martínez, M., Silva-Fragoso, A., 2018, Cenozoic magmatism and extension in western Mexico: Linking the Sierra Madre Occidental silicic large igneous province and the Comondú Group with the Gulf of California Rift: Earth-Science Reviews, 183, 115-152.

García-Palomo, A., Macías, J., Garduño, V., 2000, Miocene to recent structural evolution of the Nevado de Toluca Volcano región, Central Mexico: Tectonophysics, 318, 281-302.

Gómez-Tuena, A., Carrasco-Núñez, G., 2000, Cerro Grande volcano: the evolution of a Miocene stratocone in the early Trans-Mexican Volcanic Belt: Tectonophysics, 318, 249-280.

Gómez-Tuena, A., Orozco-Esquivel, T., Ferrari, L., 2005, Petrogénesis ígnea de la Faja Volcánica Transmexicana: Boletín de la Sociedad Geológica Mexicana, Volumen Conmemorativo del Centenario, Temas Selectos de la Geología Mexicana, LVII (3), 229-287.

Gómez-Tuena, A., Mori, L., Rincón-Herrera, N., Ortega-Gutiérrez, F., Solé, J., Iriondo, A., 2008, The origin of a primitive trondhemite from TransMexican Volcanic Belt and its implications for the construction of a modern continental arc: Geology, 30. 41-474.

Hanyu, T., Tatsumi, Y., Nakai, S., Chang, Q., Miyazaki, T., Sato, K., Tani, K., 2006, Contribution of slab melting and slab dehydration to magmatism in the NE Japan arc for the last $25 \mathrm{Myr}$ : Constraints from geochemistry. Geochemistry Geophysics Geosystems, 7, Q08002, doi:10.1029/2005GC001220.

Hart, S., Allegre, C., 1980, Trace-element constraints on magma genesis, en Hargraves, R. (ed), Physics of magmatic processes: Princeton University Press, $585 \mathrm{pp}$.

Hupper, H.E., Sparks, R.S., 1988, The generation of granitic magmas by intrusion of basalt into continental crust: Journal of Petrology, 29, 599-642.

Irvine, T., Baragar, W., 1971, Source, A guide to the chemical classification of the common volcanic rocks: Canadian Journal of Earth Sciences, 8, 523-548.

Kelleher, P., Cameron, K., 1990, The Geochemistry of the Mono CratersMono Lake Islands Volcanic Complex, Eastern California: Journal of Geophysical Research, 95(B11), 17643-17659. https://doi.org/10.1029/ JB095iB11p17643

Klitgord, K., Mammerickx, J., 1982, Northern East Pacific Rise: magnetic anomaly and bathymetric framework: Journal of Geophysical Research, 87(B8), 6725-6750, https://doi.org/10.1029/JB087iB08p06725

Le Bas, M., Le Maitre, R., Streckeisen, A., Zanetin, B., 1986, A chemical classification of volcanic rocks on the total alkali-silica diagram: Journal of Petrology, v. 27, 745-750 pp.

Lenhardt, N., Böhnel, H., Hinderer, M., Homung, J., Torres-Alvarado, I., Wemmer, K., 2010, Petrology, magnetostratigraphy and geochronology of the Miocene volcaniclastic Tepoztlán Formation: implications for the initiation of the Transmexican Volcanic Belt (Central Mexico), Bulletin Volcanology, 72, 817-832.

López-Ruiz, J., 1994, Modelización geoquímica de los procesos de mezcla: Estudios geológicos, 50, 323-339.

Lozano-Santa Cruz, R., Verma, S.P., Girón, P., Velasco, F., Morán-Zenteno, D., Viera, D.F., Chávez, G., 1995, Calibración preliminar de Fluorescencia de Rayos-X para análisis cuantitativo de elementos mayores en rocas ígneas: Actas INAGEQ, 1, 203-208.

Luhr, J.F., 2002, Petrology and geochemistry of the 1991 and 1998-1999 lava flows from Volcán de Colima, México: Implications for the end of the current eruptive cycle: Journal of Volcanology and Geothermal Research, $117,169-194$

Macías, J.L., Sosa-Ceballos, G., Arce, J.L., Gardner, J. Saucedo, R., ValdezMoreno, G., 2017, Storage conditions and magma processes triggering the 1818 A.D. Plinian eruption of Volcán de Colima: Journal of Volcanology and Geothermal Research, 340, 117-129.

Montero, E., 2012, La crisis de las tierras raras, un testimonio de la irracionalidad de nuestro modelo económico (Primera parte), Cátedra RELEC, Electrónica/Comunicaciones y Sostentabilidad, Universidad de Cádiz, 53 pp.

Mooser, F., 1972, The Mexican volcanic belt structure and tectonics: Geofisica Internacional, 12, 55-70.

Mori, L., Gómez-Tuena, A., Cai, Y., Goldstein, S., 2007, Effects of prolonged flat subduction on the Miocene magmatic record on central Trans-Mexican Volcanic Belt: Chemical Geology, 244, 452-473.

Nixon, G., 1982, The relationship between Quaternary volcanism in central Mexico and seismisity and structure of subducted ocean lithosphere: Geological Society of American Bulletin, 93, 514-523.

Nixon, G., Demant, A., Armstrong, R., Harakal, J., 1987, K-Ar and geologic data bearing on the age and evolution of the Trans-Mexican Volcanic Belt: Geofisica Internacional, 26, 109-158.

Norini, G., Capra, L., Borselli, l., Zuniga, F. R., Solari, L., and Sarocchi, D., 2010, Large scale landslides triggered by Quaternary tectonics in the Acamabay graben, Mexico: online in Wiley Inter Science: Earth Surface Processes and Landforms, 35, 1445-1455, https://doi.org/10.1002/esp.1987

Pardo, M., Suárez, G., 1993, Steep subduction geometry of the Rivera plate beneath the Jalisco Block in western Mexico: Geophysical Research Letters, 20, 2391-2394. DOI: 10.1029/93GL02794

Pardo, M., Suárez, G., 1995, Shape of the subducted Rivera and Cocos Plate beneath of Jalisco Block in western Mexico: Geophysical Research, 100, 12357-12373.

Pasquaré, G., Garduño, V., Tibaldi, A., Ferrari, M., 1988, Stress pattern evolution in the central sector of the Mexican Volcanic Belt: Tectonophysics, 146, 353-364.

Patino, L.C., Carr, M.J., Feigenson M.D., 2000, Local and regional variations in Central American arc lavas controlled by variations in subducted sediment input: Contributions to Mineralogy and Petrology, 138, 265-283.

Paton, Ch., Woodhead, J., Hellstrom, J., Hergt, J., Greig, A., 2010, Improved laser ablation $\mathrm{U}-\mathrm{Pb}$ zircon geochronolopgy through robust downhole fractionation correction: Geochemistry, Geophysics, Geosystems, 11, Q0AA06, doi:10.1029/2009GC002618

Pearce, J.A., Stern, R.J., Bloomer, S.H., Fryer, P., 2005, Geochemical mapping of the Mariana arc-basin system: Implications for the nature and distribution of subduction components, Geochemistry Geophysics. Geosystems., 6, Q07006, doi:10.1029/2004GC000895.

Pedrazzi, D., Aguirre-Díaz, G.J., Sunyé-Puchol, Becerril, L., Miggins, D., 2018, Volcano stratigraphy and physical characterization of the San Mateo Pomez unit, Cerritos member: Temascalcingo volcano, Central Mexico: Journal of Volcanology and Geothermal Research, doi.10.1016/j. jvolreores.2018.10.007.

Pérez-Venzor, J., Aranda-Gómez, J., McDowell, F., Solorio-Munguía, J., 1996, Geología del volcán Palo Huérfano, Guanajuato, México: Revista Mexicana de Ciencias Geológicas, 13, 174-183.

Petrus, J., Kamber, B., 2012, Vizualage: A novel approach to laser ablation ICPMS-U-Pb. Geochronology data reduction: Geostandars and geoanalitycal research, 36, 247-270.

Quintero-Legorreta, O., 2002, Análisis estructural de fallas potencialmente activas: Boletín de la Sociedad Geológica Mexicana, LV(1), 1-11. 
Robin, C., Cantagrel, J., 1982, Le Pico de Orizaba (Mexique). Structure et evolution d' un grand volcán andesitique complexe: Bulletin of Volcanology, 45, 299-315.

Roldán-Quintana, J., Aguirre-Díaz, G., Rodríguez-Castañeda J.L., 2011, Depósito de avalancha de escombros del volcán Temascalcingo en el graben de Acambay, Estado de México: Revista Mexicana de Ciencias Geológicas, 28(1), 118-131.

Rollinson, A., 1993, Using Geochemical Data: evaluation, presentation, interpretation: New York, John Wiley \& Sons, Inc., 102-170.

Rosas-Elguera, J., Alva-Valdivia, L., Goguitchaichvili, A., Urrutia-Fucuguachi, J., Ortega-Rivera, M. A., Archibald, D., 2003, Counterclockwise rotation of the Michoacan Block: implications for the tectonics of western Mexico: International Geology Review, 45, 814-826.

Ruiz, J., Patchett, P.J., Arculus, R.J., 1988, Nd-Sr isotope composition of lower crustal xenoliths: evidence for the origin of mid-Tertiary felsic volcanic in Mexico: Contributions to Mineralogy and Petrology, 99, 36-43.

Ruiz, J., Patchett, P.J., Arculus, R.J., 1990, Reply to "Comments on Nd-Sr isotope composition of lower crustal xenoliths: evidence for the origin of mid-Tertiary volcanic in Mexico", by K. L. Cameron and J. V. Robinson: Contributions to Mineralogy and Petrology, 104, 615-618.

Sánchez-Rubio, G., 1984, Cenozoic volcanism in Toluca-Amealco region, central Mexico. University of London, Imperial College of Sciences and Technology, Tesis de Maestría, 275 pp.

Schaaf, P., Stimac, J., Siebe, C., Macías, J.L., 2005, Geochemical evidence for mantle origin and crustal processes in volcanic rocks from Popocatépetl and surrounding monogenetic volcanoes, central Mexico: Journal of Petrology, 46, 1243-1282.

Silva-Mora, L., 1997, Geología volcánica y carácter químico preliminar de las rocas de la región de Tula-Polotitlán, estados de Hidalgo, México y Querétaro, México: Revista Mexicana de Ciencias Geológicas, 14(1), 50-77.

Siebe, C., Abrams, M., Macías, J.L., Obenholzner, J., 1996, Repeated volcanic disasters in Prehispanic time at Popocatépetl, central Mexico: Past key to the future?: Geology, 24, 5, 399-402.

Smith, R.D., Cameron, K.L., McDowell, F.W., Niemeyer, S., Sampson, D.E., 1996, Generation of voluminous silicic magmas and formation of mid-Cenozoic crust beneath north-central Mexico-evidence from ignimbrites, associated lavas, deep crustal granulites, and mantle pyroxenites: Contributions to Mineralogy and Petrology, 123, 375-389.

Solari, L., Gómez-Tuena, A., Bernal, J., Pérez-Arvizu, M., 2010, U-Pb zircon geochronology with an integrated LA-ICP-MS microanalytical workstation: Achievements in precision and accuracy: Geostandards and Geoanalytical Research, 34, 5-18.

Solari, L., Ortega-Obregón, C., Bernal, J.P., 2015, Chemical Geology: U-Pb zircon geochronology by LAICPMS combined with thermal annealing: Achievements in precision and accuracy on dating standard and unknown samples, 414, 109-123.
Sun, S.S., McDonough, W.F., 1989, Chemical and isotopic systematic of oceanic basalts: Implications for mantle compositions and processes, en Sanders A.D., Norry M.J., (eds.), Magmatism in ocean basins: Geological Society of London, Special Publication, 42, 313-345.

Sunyé-Puchol, I., Lacan, P., Ortuño, M., Villamor, P., Zúñiga, F.R., Langridge, R.M., Aguirre-Díaz, G.J., Lawton, T.F., 2015, La falla San Mateo: nuevas evidencias paleosismológicas de fallamiento activo en el graben de Acambay, México: Revista Mexicana de Ciencias Geológicas, 32(3), 361-376.

Suter, M., Quintero, O., Johnson, C., 1992, Active faults and state of stress in the central part of the Trans-Mexican Volcanic Belt. 1. The Venta of Bravo fault: Journal of Geophysical Research, 97, 11983-11994.

Suter, M., Quintero, O., Lopéz, M., Aguirre, G., Ferrari, L., 1995, The Acambay graben: Active intra arc extension in the Trans-Mexican Volcanic Belt: Tectonics, 14, 1245-1262.

Torres-Alvarado, I.S., Lenhardt, N., Arce, J.L., Hinderer, M., 2016, Geochemical and isotopic composition of volcanic rocks of the heterogeneous Miocene ( 23-19 Ma) Tepoztlán Formation, early Transmexican Volcanic Belt, Mexico. Journal of Volcanology Geothermal, 316, 72-84.

Torres-Orozco, R., 2012, Vulcanismo efusivo en el área del Nevado de Toluca: distribución y genesis de magmas: Universidad Nacional Autónoma de México, Posgrado en Ciencias de la Tierra, Tesis de Maestría, 138 pp.

Urrutia-Fuguachi, J., Bohnel, H., 1987, Tectonic interpretation of the TransMexican Volcanic Belt: Tectonophysics, 138, 319-323.

Urrutia-Fuguachi, J., Del Castillo, L., 1977, Un modelo del Eje Volcánico Mexicano: Boletín de la Sociedad Geológica Mexicana, 38, 18-28.

Valdéz-Moreno, G., Aguirre-Díaz, G., López-Martínez, M., 1998, El volcán La Joya, estados de Querétaro y Guanajuato-un estratovolcán miocénico del Cinturón Volcánico Mexicano: Revista Mexicana de Ciencias Geológicas, 15(2), 181-197.

Velasco-Tapia, F., 2003, Procesos de evolución magmática en la Sierra de Chichinautzin, Cinturón Volcánico Mexicano: Ciencia UANL, 6, 45-52.

Venegas, S., Herrera, F., Maciel, R., 1985, Algunas características de la Faja Volcánica Mexicana y sus recursos geotérmicos: Geofísica Internacional, 24, 97-157.

Wark, D. A., 1991, Oligocene ash flow volcanism, northern Sierra Madre Occidental: Role of mafic and intermediate-composition magmas in rhyolite genesis: Journal of Geophysical Research, 96, 13389-13411.

Manuscrito recibido: marzo 17, 2018

Manuscrito corregido recibido: octubre 18, 2018

Manuscrito aceptado: noviembre 20, 2018 